\title{
OPEN 3-D ocean particle tracking modeling reveals extensive vertical movement and downstream interdependence of closed areas in the northwest Atlantic
}

\author{
S. Wang ${ }^{1}$, E. L. Kenchington ${ }^{1 凶}$, Z. Wang ${ }^{1}$, I. Yashayaev ${ }^{1}$ \& A. J. Davies ${ }^{2}$
}

Novel 3-D passive particle tracking experiments were performed in the northwest Atlantic to elucidate connectivity among areas closed to protect vulnerable marine ecosystems. We examined (1) the degree of vertical movement of particles released at different depths and locations; (2) the location of potential source populations for the deep-sea taxa protected by the closures; and (3) the degree of functional connectivity. A long-term oceanographic dataset (EN4) was queried to characterize the temperature and salinity regimes in each of the closed areas as a basis for interpreting recently published climate change projections. Using the Parcels Lagrangian particle tracking framework and the BNAM hydrodynamic model, we found enhanced connectivity over previously developed 2-D models and unexpected, current-driven, strong (to a maximum of about $1340 \mathrm{~m}$ ) downward displacement at depth (450, 1000 and $2250 \mathrm{~m}$ ), with weaker upward displacement except for the release depth of $2250 \mathrm{~m}$ which showed upward movement of $955 \mathrm{~m}$ with a drift duration of 3 months. The current velocities create down-stream interdependence among closed areas and allow redundancy to develop in some of the areas of the network, with some of the larger areas also showing retention. Source populations for sponges in the upstream closure are likely in adjacent waters of the Canadian continental shelf. Collectively this information can be used to inform management decisions related to the size and placement of these closed areas, and vertical velocity surfaces have potential for use in species distribution modeling of benthic species and habitats.

The large-scale distributions of deep-sea invertebrate species are strongly associated with hydrographic features, largely the water mass characteristics of temperature and salinity ${ }^{1,2}$. This relationship has underpinned the adoption of species distribution models to predict the presence, abundance or biomass of these species through both space and time ${ }^{3}$. However, at local scales, distribution patterns are more strongly influenced by topographically interacting hydrodynamic processes such as currents, downwelling and other mechanisms ${ }^{4}$. Understanding how the distribution of species are influenced at varying scales is a priority for conservation and management of vulnerable marine species. Multiple tools and approaches are available, but most recently Lagrangian particle tracking (LPT) has emerged as an important tool for assessing structural connectivity in the deep sea ${ }^{5-8}$. In such models, virtual particles are advected by the flow fields generated by numerical models ${ }^{9}$, and virtual behavior can be added to the particles so that they can act as active drifters, i.e., larvae. When combined with hydrodynamic data, this tool has great potential to enhance our understanding of species distributions and to predict functional connectivity.

The northwest Atlantic contains a diverse array of benthic habitats ${ }^{10-14}$, and although 285 epibenthic invertebrate taxa have been identified from this region to date ${ }^{13}$, conservation efforts have largely focussed on vulnerable marine ecosystems (VMEs) characterized by fragile, long-lived species that are vulnerable to impacts by bottomcontact fishing gears ${ }^{15}$. The regional fisheries management organization operating in this area beyond national jurisdiction, the Northwest Atlantic Fisheries Organization (NAFO), has closed 14 areas on the Flemish Cap and the Tail of Grand Bank (Fig. 1) to protect deep-sea corals, sea pens and sponges ${ }^{16}$. Closed Areas 1-6 were

${ }^{1}$ Department of Fisheries and Oceans Canada, Bedford Institute of Oceanography, 1 Challenger Drive, Dartmouth, NS B2Y 4A2, Canada. ${ }^{2}$ Department of Biological Sciences, Center for Biotechnology and Life Sciences, University of Rhode Island, 120 Flagg Road, Kingston, RI 02881, USA. ${ }^{\bowtie}$ email: Ellen.Kenchington@dfo-mpo.gc.ca 

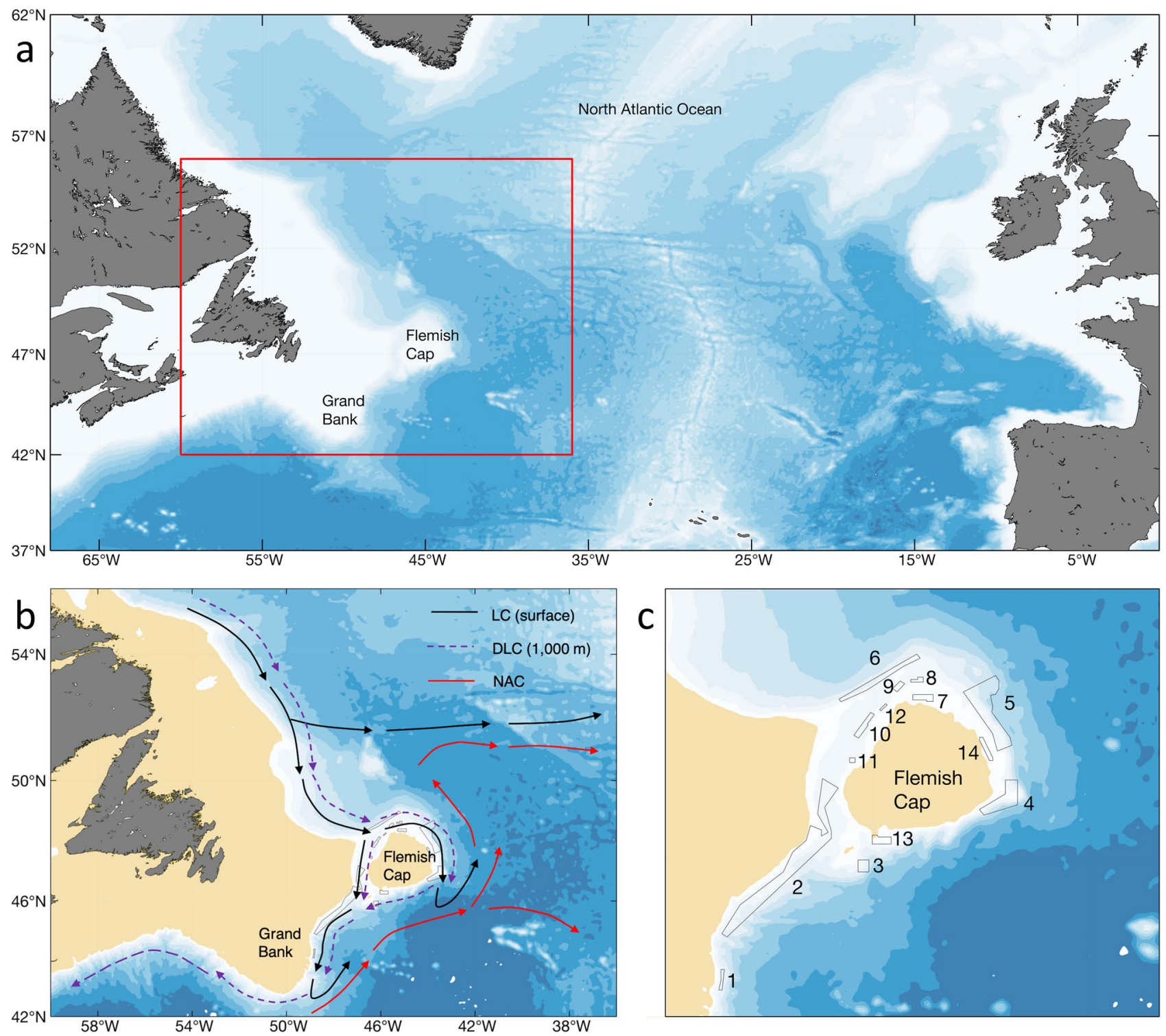

Figure 1. Maps Detailing the Study Area. (a) The position of Flemish Cap and Grand Bank within the North Atlantic; (b) inset from (a) (red outline) showing a schematic diagram for the pathways of the major currents in the region: the Labrador Current (LC) at the surface, the Deep Labrador Current (DLC) at $1000 \mathrm{~m}$ and the North Atlantic Current (NAC); (c) locations of the 14 NAFO closed areas on Flemish Cap and the Tail of Grand Bank and their associated area codes. The maps were generated using bathymetry and coastline data produced and made publically available by the NOAA National Centers for Environmental Information (NCEI). The ETOPO1 Ice Surface (https://doi.org/10.7289/V5C8276M) arc-minute global relief model of the Earth's surface (https://www.ngdc.noaa.gov/mgg/global/) was used to generate bathymetry and the Global Self-consistent, Hierarchical, High-resolution Geography Database (GSHHG; https:/www.ngdc.noaa.gov/mgg/shorelines/ gshhs.html) was used to produce co-ordinates for a high-resolution coastline and both plotted using Matlab version 9.5 software (https://www.mathworks.com) with the M_Map mapping package (version 1.4 m, created by R. Pawlowicz, https://www.eoas.ubc.ca/ rich/map.html).

closed primarily to protect deep-sea sponge grounds, Areas 7-12 and 14 were primarily closed to protect sea pens, and Areas 2, 4, 5 and 13 to protect large gorgonian corals ${ }^{7}$. These closed areas occur in deep water ranging from $483 \mathrm{~m}$ (Area 2) to $2754 \mathrm{~m}$ depth (Area 4). While place-based management measures can offer protection from direct impacts of bottom-contact fishing gears, the long-term viability of the protected populations will depend on identifying and protecting sources of recruitment and connectivity pathways ${ }^{17}$.

In the Flemish Cap region where most of these closures are found (centered around $47^{\circ} \mathrm{N}, 45^{\circ} \mathrm{W}$ with a $200 \mathrm{~km}$ radius at the $500 \mathrm{~m}$ isobath), two major currents, the Labrador Current (LC) and the North Atlantic Current (NAC) carry water masses with different origins ${ }^{18,19}$. The LC, including its deep branch, carries Denmark Strait Overflow Water (DSOW), Labrador Sea Water (LSW), and Iceland-Scotland Overflow Water (ISOW) from the north into this region, while the NAC transports warm and saline Gulf Stream water from the south. The bathymetry of the slopes creates topographic obstacles to water flows that strongly affects the currents (Fig. 1). 


\begin{tabular}{|c|c|c|c|c|c|}
\hline Particle release depth & Drift duration & Minimum depth reached (m) & $\begin{array}{l}\text { Minimum depth reached by the } \\
\text { first } 50 \% \text { of particles (m) }\end{array}$ & Maximum depth reached (m) & $\begin{array}{l}\text { Maximum depth reached by the } \\
\text { first } 50 \% \text { of particles (m) }\end{array}$ \\
\hline \multirow{3}{*}{ Surface } & 2 weeks & & & 0.78 & 0.55 \\
\hline & 1 month & & & 1.40 & 0.59 \\
\hline & 3 months & & & 2.90 & 0.69 \\
\hline \multirow{3}{*}{$100 \mathrm{~m}$} & 2 weeks & 59.7 & 100.0 & 218.9 & 121.9 \\
\hline & 1 month & 47.4 & 100.0 & 294.3 & 136.9 \\
\hline & 3 months & 28.1 & 99.7 & 565.3 & 146.8 \\
\hline \multirow{3}{*}{$450 \mathrm{~m}$} & 2 weeks & 331.0 & 441.8 & 853.0 & 494.7 \\
\hline & 1 month & 331.0 & 439.5 & 1110.6 & 517.8 \\
\hline & 3 months & 316.9 & 437.3 & 1500.7 & 549.9 \\
\hline \multirow{3}{*}{$1000 \mathrm{~m}$} & 2 weeks & 727.1 & 960.7 & 2144.1 & 1087.1 \\
\hline & 1 month & 640.9 & 951.3 & 2285.6 & 1132.1 \\
\hline & 3 months & 607.5 & 947.0 & 2341.8 & 1191.5 \\
\hline \multirow{3}{*}{$2250 \mathrm{~m}$} & 2 weeks & 1771.9 & 2250.0 & 3029.8 & 2446.4 \\
\hline & 1 month & 1378.6 & 2235.1 & 3238.5 & 2502.4 \\
\hline & 3 months & 1298.2 & 2209.8 & 3446.4 & 2565.1 \\
\hline
\end{tabular}

Table 1. Vertical particle displacements. Depths for particles released under different model depth and drift duration scenarios to examine vertical movement. All scenarios used forward-tracked 3-D models and the average current for five particle release depths (surface, $100 \mathrm{~m}, 450 \mathrm{~m}, 1000 \mathrm{~m}$ and $2250 \mathrm{~m}$ ). The minimum and maximum depths for the termination of the first $50 \%$ of particles are provided.

The LC bifurcates to the northwest of Flemish Cap, one branch flowing through the Flemish Pass and the other circulating around Flemish Cap in a clockwise direction (Fig. 1). In the surface waters the LC interacts with the NAC to the east and south of Flemish Cap. Given this complex hydrographic regime, it is not surprising to find that regional species distribution models for deep-sea sponges, large gorgonian corals, and sea pens all identify hydrographic variables as important drivers of occurrence $e^{7,10,11,13}$.

Kenchington et al. ${ }^{7}$ used a 2-D LPT model to evaluate structural and functional connectivity among the 14 areas that were closed to protect vulnerable marine ecosystems by NAFO. They found that the regional pattern of currents led to downstream interdependence between some of the closed areas. A system of weakly-connected closed areas to protect sea pen VMEs on Flemish Cap was identified and species distribution models were used to evaluate potential source areas. That work had various limitations ${ }^{20}$, most notably particle tracking was limited to relatively shallow depth zones using vertical averages of the velocity fields for each depth interval modeled: 0-5 $\mathrm{m}$ (surface) and 95-105 $\mathrm{m}(100 \mathrm{~m})$, and particle tracking was only run with horizontal movement (2-D). Here, we build on that work by applying 3-D LPT models to assess connectivity among closed areas put in place by NAFO. Our experiments are used to simulate larval transport and show how temporal and spatial ocean model changes affect dispersal. We performed three different simulation experiments aimed at determining different aspects of biophysical connectivity among the 14 closed areas. We specifically examine: (1) the degree of vertical movement of particles released at different depths and locations directed by the position of the closed areas; (2) the location of potential source populations for the deep-sea sponges, large gorgonian corals, and sea pens protected by the closed areas; and (3) the degree of functional connectivity between the closed areas taking into consideration the spawning times of the VME indicator species present. Lastly, a long-term oceanographic dataset (EN4) was queried to characterize the temperature and salinity regimes in each of the closed areas as a basis for interpreting climate change projections ${ }^{21}$.

\section{Results}

Vertical movements in 3-D models. Particles released at the surface generally stayed within close proximity to the surface under all time durations due to strong surface currents leading to rapid horizontal dispersion of the particles (Table 1, Fig. 2). Particles released at $100 \mathrm{~m}$ stayed near that depth unless left for 3 months at which time the maximum depth reached showed strong downward movement of over $400 \mathrm{~m}$ (Fig. 2a, Table 1). However, the maximum depth reached by $50 \%$ of the particles was only $146.8 \mathrm{~m}$ (Table 1), indicating that the particles showed greater dispersion at this depth and duration. The vertical movement of particles showed stronger downward maximum vertical movements for passive particles released at $450 \mathrm{~m}, 1000 \mathrm{~m}$ and $2250 \mathrm{~m}$ depths for all 3 drift durations (2 weeks, 1 month and 3 months) (Table 1, Fig. 2a). Particles released at $1000 \mathrm{~m}$ and $2250 \mathrm{~m}$ showed the strongest downward movement (Table 1) with maximum displacement of over $1000 \mathrm{~m}$ evident even under a one-month drift duration (Table 1 ). However, the maximum depth reached by $50 \%$ of the particles was always less than $300 \mathrm{~m}$ at these release depths and durations (Table 1).

Upward movement was generally not as extensive as the downward (Table 1, Fig. 2b), with maximum upward displacements of less than $\sim 75 \mathrm{~m}$ at a release depth of $100 \mathrm{~m}$, less than $\sim 135 \mathrm{~m}$ at release depth of $450 \mathrm{~m}$, less than $\sim 395 \mathrm{~m}$ at release depth of $1000 \mathrm{~m}$, and less than $\sim 955 \mathrm{~m}$ at a release depth of $2250 \mathrm{~m}$ (Table 1); all were achieved under longer drift durations. For $50 \%$ of the particles, the minimum depth reached was similar to that of the release depth. 
a Downward Movement
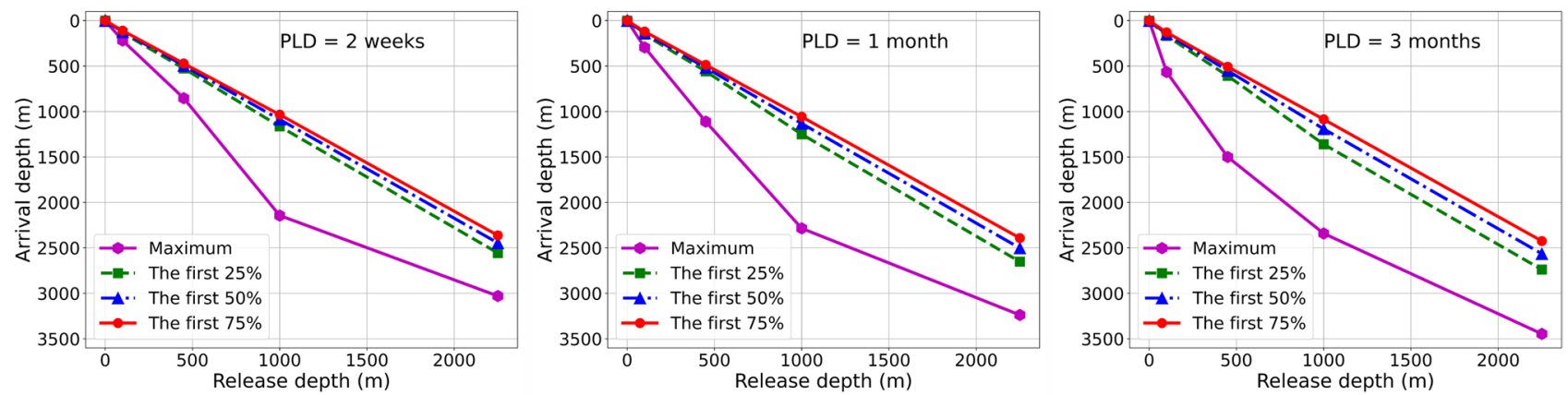

\section{b Upward Movement}
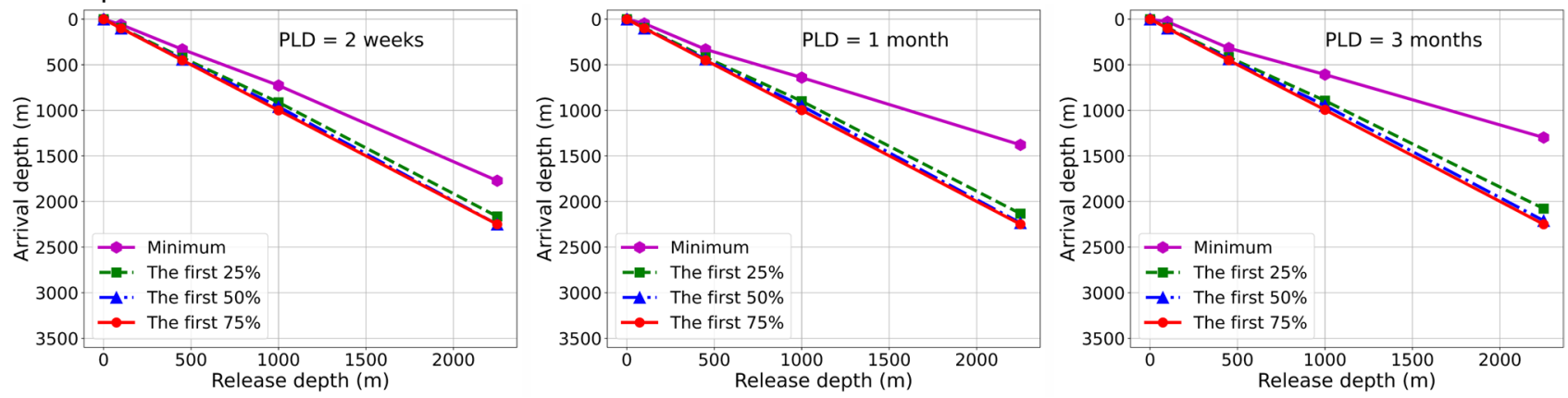

Figure 2. Vertical Particle Movements. (a) downward and (b) upward minimum depths that forward-tracked particles reached under each of 3 pelagic larval drift durations (PLD) using 3-D models and the average current for 5 particle release depths (surface, $100 \mathrm{~m}, 450 \mathrm{~m}, 1000 \mathrm{~m}$ and $2250 \mathrm{~m}$ ). The depths for which the arrival of the first 25\% (green lines and symbols), 50\% (blue lines and symbols) and 75\% (red lines and symbols) of particles are shown for each scenario.

Both the upward and downward displacement by the $25 \%, 50 \%$, and $75 \%$ of particles was much less pronounced than the minimum and maximum depths reached (Fig. 2, Table 1), indicating that the majority of particles typically stayed in the vicinity of their release depth (Table 1). Particles released at $100 \mathrm{~m}$ and $450 \mathrm{~m}$ stayed at that depth or slightly deeper within 1 month duration, but if left for 3 months they also showed downward displacement of around $70 \mathrm{~m}$ and $150 \mathrm{~m}$ for $25 \%$ particles at each depth respectively (Fig. 2). Particles released at $1000 \mathrm{~m}$ and $2250 \mathrm{~m}$ showed the strongest downward movement with a displacement of around $360 \mathrm{~m}$ and $500 \mathrm{~m}$ with 3-month drift duration for $25 \%$ particles at each depth respectively (Fig. 2). Upward movement was not as great as the downward, with upward displacements of $25 \%$ particles around $100 \mathrm{~m}$ (release depth $1000 \mathrm{~m}$ ) and $180 \mathrm{~m}$ (release depth $2250 \mathrm{~m}$ ) (Figs. 2a, 3). A seasonal evolution of flow pattern is known to exist around Flemish Cap ${ }^{22,23}$. Downward movements by the first $50 \%$ of sorted particles remained prevalent for all seasons and release depths evaluated, with little vertical movement at the surface and $100 \mathrm{~m}$ water depth (Fig. 3a,b). Increasingly prominent downward movements were observed in deeper water. At $450 \mathrm{~m}, 1000 \mathrm{~m}$ and $2250 \mathrm{~m}$ release depths, seasonality appeared to impact vertical travelling distances that were greater in the summer and autumn than at other seasons (Fig. 3c-e).

These results show that even though the majority of particles stayed at their release depths, there is potential for significant vertical displacement of passive particles in this region and that seasonally applied connectivity experiments with 3-D modelling are needed to give an improved interpretation of particle trajectories over models that only take into account horizontal movements ${ }^{7}$.

Identification of potential source populations. Results from particles released at $1000 \mathrm{~m}$ (which approximated the mean depth across all closed areas) over the entire spatial domain with particles passing over and ending inside one of the 14 closed areas (Fig. $4 \mathrm{a}-\mathrm{c}$ ) showed that deep-sea species around Flemish Cap likely have source populations to the north, inside Canadian waters, that were transported by the Deep Labrador Current (DLC) along the continental slope, consistent with our models of vertical displacement at this release depth (Figs. 2, 3). The proportions of particles reaching the closed areas (Fig. 4d) were higher for the areas with larger size (Areas 2, 4, 5 and 6) and highest for Area 5. Almost no particles entered Area 7 and 14 within a 1-month drift duration due to their maximum depths (718 and $688 \mathrm{~m}$ respectively) relative to the $1000 \mathrm{~m}$ release depth in this simulation. Increasing drift duration increased the proportion of particles arriving in all closed areas, as would be expected. The results of the models where particles were released from the closed areas and back-tracked, show a similar spatial distribution (Supplementary Fig. S1) to that produced from the forward models seeded over the full spatial domain at the same $1000 \mathrm{~m}$ depth (Fig. 4), although the proportion of particles reaching another closed area is much higher, as expected from the position of the release sites. Area 2 shows a higher proportion of particles in the back-tracked model for the 2 week duration, reflecting retention in this large closed 
a Release Depth: $0 \mathrm{~m}$

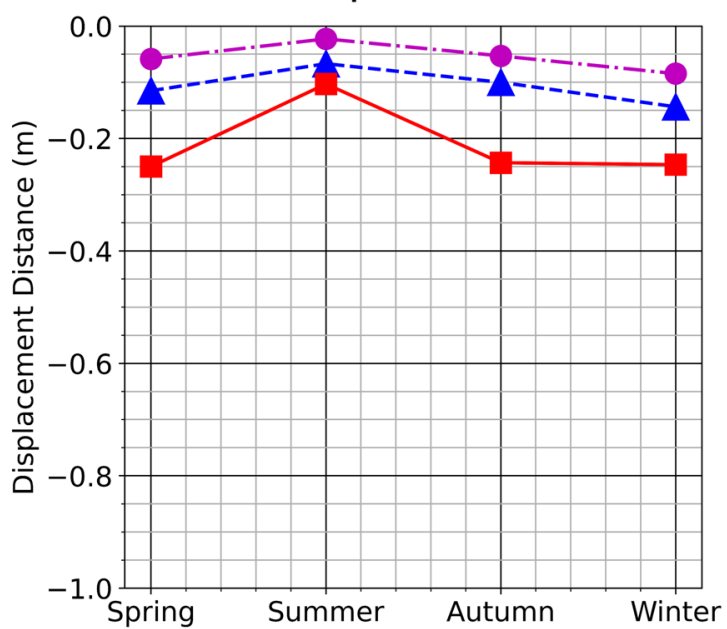

C Release Depth: 450 m

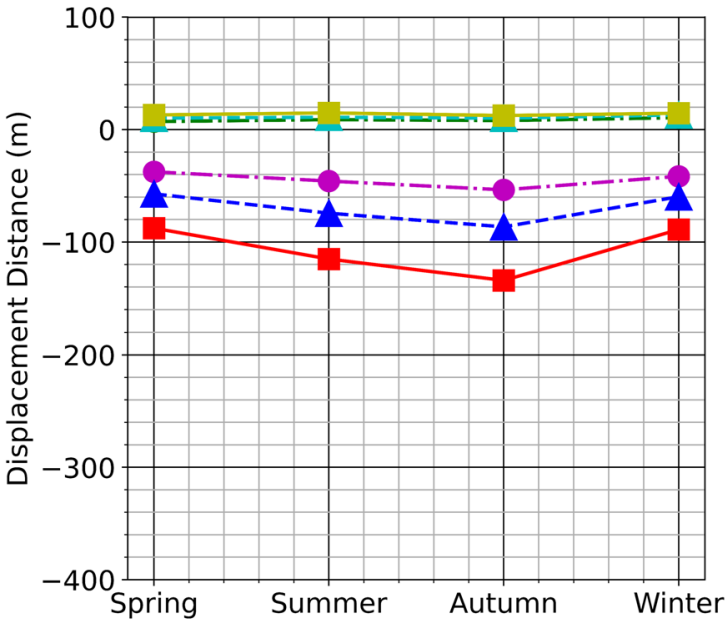

e Release Depth: 2250 m

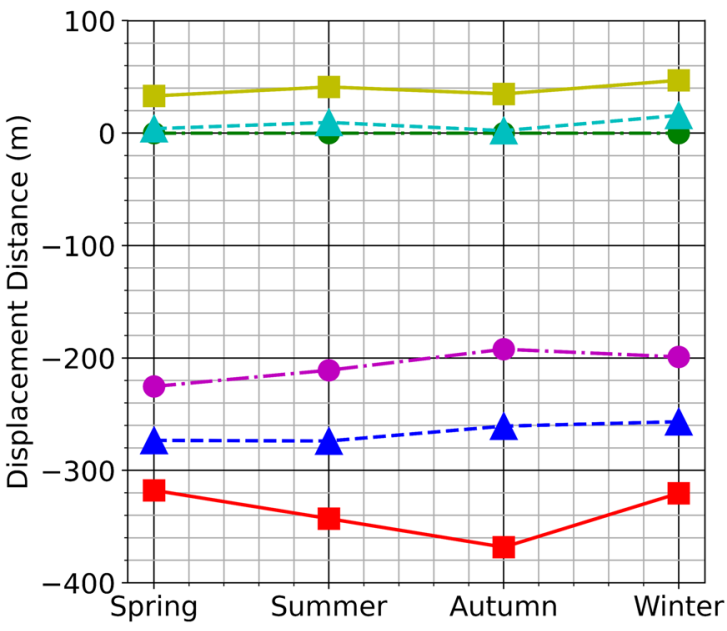

b Release Depth: 100 m

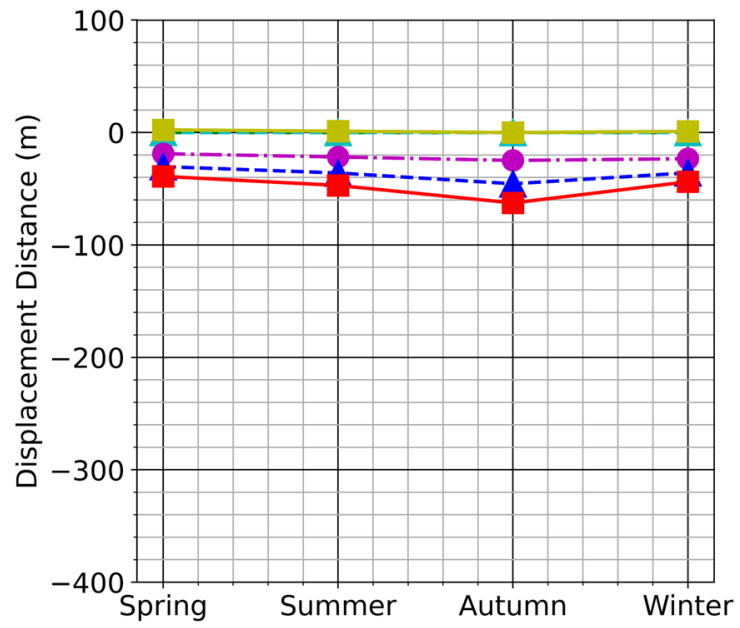

d Release Depth: $1000 \mathrm{~m}$

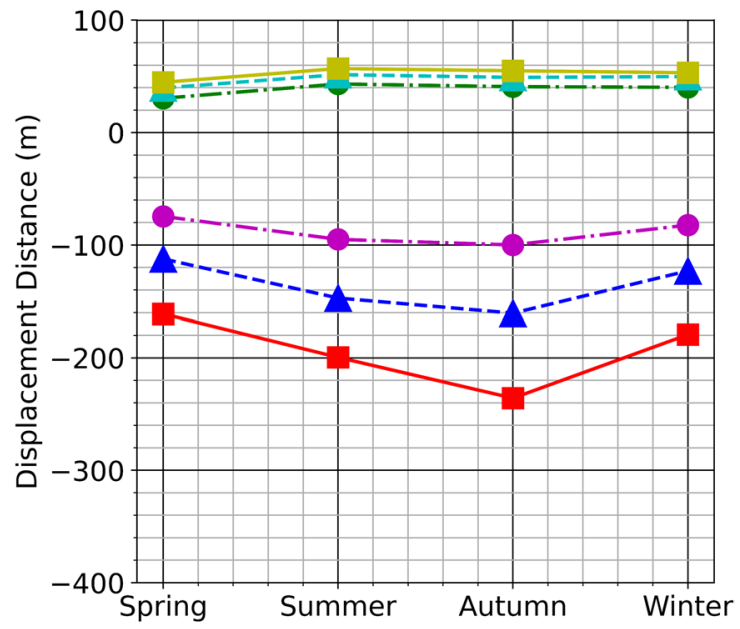

Figure 3. Seasonal Vertical Particle Displacements. Upward and downward travelling distances in each of four northern hemisphere seasons with different particle release depths $((\mathbf{a}-\mathbf{e})$ Surface, $100 \mathrm{~m}, 450 \mathrm{~m}, 1000 \mathrm{~m}$ and $2250 \mathrm{~m}$ ) and pelagic larval drift durations (PLD; 2 weeks, 1 month and 3 months) in terms of the depths at which $50 \%$ of the forward-tracked particles released where able to reach. Positive and negative values denote upward and downward movements, respectively. 

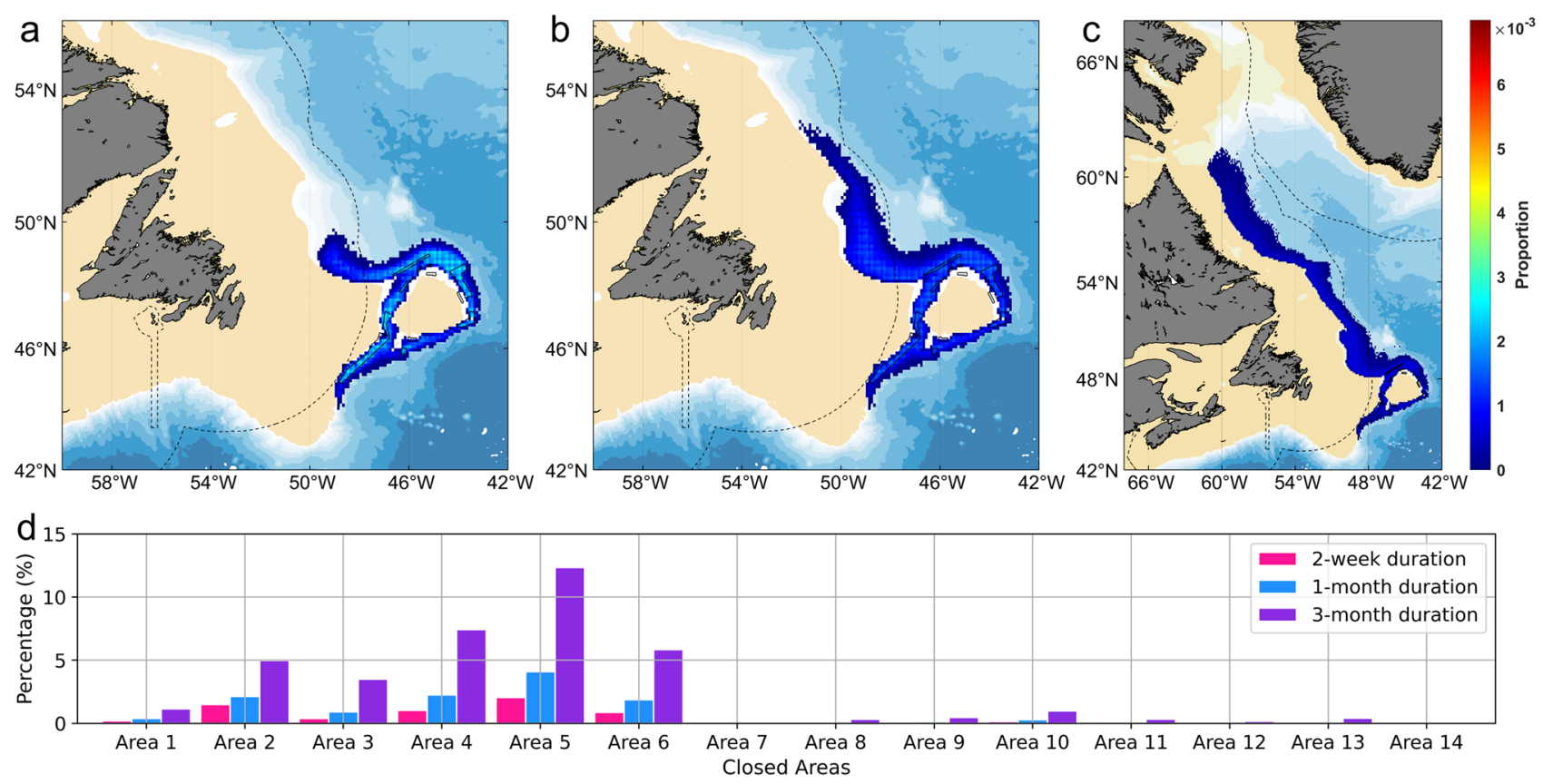

Figure 4. Potential source populations. Spatial distribution of the proportion of released particles ending in and passing over each $0.1^{\circ} \times 0.1^{\circ}$ grid cell with particles released at $1000 \mathrm{~m}$ depth and forward-tracked with drift durations of: (a) 2-week, (b) 1-month and (c) 3-month drift durations; (d) the proportion of released particles $(1000 \mathrm{~m}$ ) entering each closed area (see Fig. 1c) under three drift duration scenarios. Dashed lines indicate boundaries of national jurisdictions downloaded from the Maritime Boundaries Geodatabase, version 11, available online at https://www.marineregions.org/, https://doi.org/10.14284/382. The maps were generated using bathymetry and coastline data produced and made publically available by the NOAA National Centers for Environmental Information (NCEI). The ETOPO1 Ice Surface (https://doi.org/10.7289/V5C8276M) arcminute global relief model of the Earth's surface (https://www.ngdc.noaa.gov/mgg/global/) was used to generate bathymetry and the Global Self-consistent, Hierarchical, High-resolution Geography Database (GSHHG; https://www.ngdc.noaa.gov/mgg/shorelines/gshhs.html) was used to produce co-ordinates for a high-resolution coastline and both plotted using Matlab version 9.5 software (https://www.mathworks.com) with the M_Map mapping package (version $1.4 \mathrm{~m}$, created by R. Pawlowicz, https://www.eoas.ubc.ca/ rich/map.html).

area (Supplementary Table S5), which reduced in proportion at the 1 month and 3 month durations as particles left the closed area (Supplementary Fig. S1).

Functional connectivity of sponges, sea pens and large Gorgonian corals. Large-sized sponges. The connectivity amongst areas closed to protect sponges (Areas 1-6) was assessed after a pelagic larval duration (PLD) of 2 weeks, which approximates the larval duration of deep-sea sponges ${ }^{24}$. Dominated by the Deep Labrador Current, a clockwise connection around Flemish Cap was observed in both forward- and backtracking models with downstream interdependence and minimal redundancy (Fig. 5a, Supplementary Fig. S2). Six connections between areas closed to protect sponges were observed with models using average oceanographic values, at the minimum and middle depths of the mean depth ranges for the combined areas, while only 5 connections were observed at the maximum depth where the connection between Area 6 and Area 4 was not found in the forward-tracking model but was picked up in the backward-tracking model (Supplementary Table S1). A seventh connection between Area 5 and Area 3 was made in summer only at $1245 \mathrm{~m}$. Retention within a closed area increased with depth and was observed in Areas 1, 2, 3, 4, 5, and 6 at different depths/seasons, with greater retention being identified in the backward-tracking models (Supplementary Table S1). Area 6 had downstream links with Area 5 and Area 4 for all three concerned depths. No particles released from Area 6 reached Area 4 at the release depth of $1684 \mathrm{~m}$ in the forward-tracking models (Fig. 5) although the back-tracking model picked up a much higher proportion of particles in Area 6 (Supplementary Fig. S2, Supplementary Table S1). There was potential for Area 5 to connect with Area 4, thereby conferring some redundancy for Area 4 . It is very likely that Areas 4, 3 and 2 make connections with Area 3, 2 and 1, respectively (Fig. 5, Supplementary Fig. S2, Supplementary Table S1). These connections had relatively short arrival times of 10 days or less (Supplementary Fig. S5). Particles released from Area 5 at $1245 \mathrm{~m}$ depth reached another closed area (likely Area 4) peaking at 6 days, while complimentary particles backtracked from Area 4 showed a peak transit time of 4 days to Area 5 (inferred; Supplementary Fig. S5). The downstream chain-linking of the closed areas is evident in Fig. 5a and Supplementary Fig. S2. A large proportion of the particles released in Area 6 connect to Area 5 at all depths simulated (Fig. 5b-d; Supplementary Fig. S2). However, the redundancy in Area 4 results in it receiving the greatest percentage of the total particles released and forward-tracked at each depth scenario, ranging from $17.13 \%$ at $1245 \mathrm{~m}$ to $20.88 \%$ at $1684 \mathrm{~m}$. In comparison, the connection between Area 2 and Area 1 area was relatively weak 


\section{a}

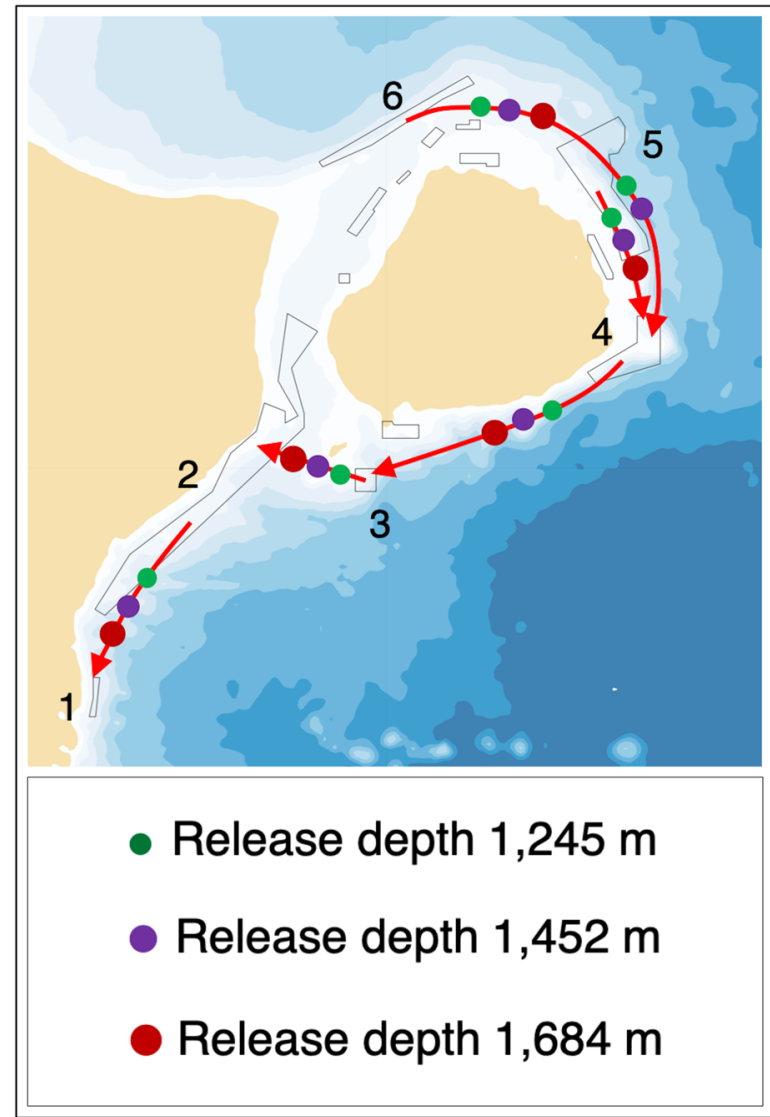

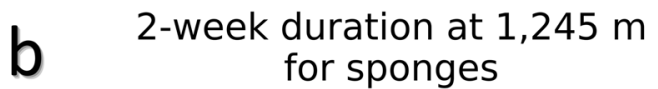

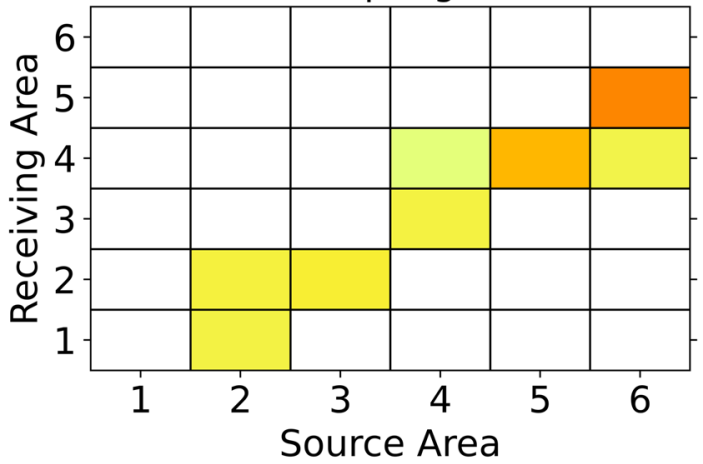

$0.00 \%$

$10.62 \%$

$17.13 \%$

$1.56 \%$

$7.70 \%$

$6.33 \%$

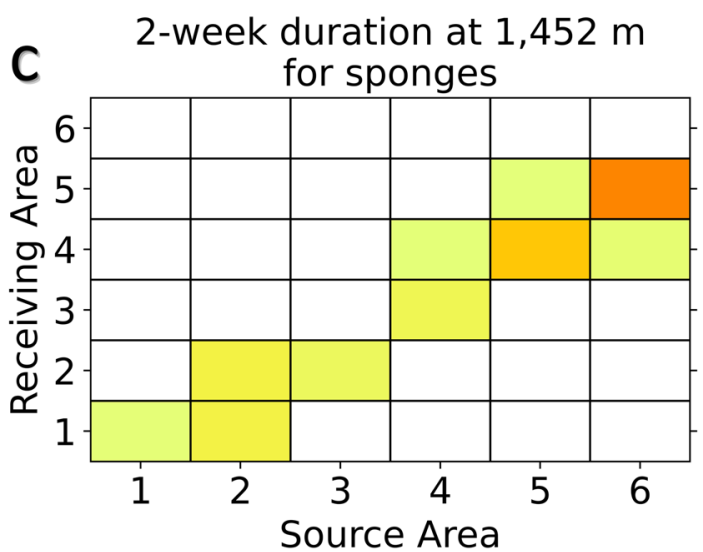

$0.00 \%$

$8.15 \%$

$17.12 \%$

$1.38 \%$

$5.12 \%$

$4.82 \%$
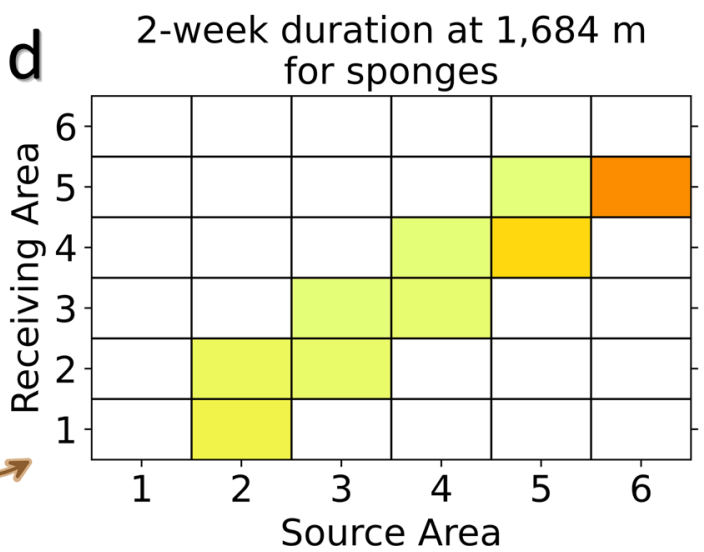

$0.00 \%$ $3.34 \%$ $20.88 \%$ $0.67 \%$ $1.27 \%$ $1.73 \%$

Proportion of particles crossing or terminating in another Closed Area

Figure 5. Functional connectivity among areas closed to protect sponges. (a) Forward-tracking connectivity pathways for particles released at 3 depths in each of the 6 areas closed to protect large-size sponges (Areas 1-6) showing chain-linking and minimal redundancy in Area 4. Drift durations were 2 weeks. The closed circles over the lines indicate particles can reach another area when released from this depth. The map was generated using bathymetry and coastline data produced and made publically available by the NOAA National Centers for Environmental Information (NCEI). The ETOPO1 Ice Surface (https://doi.org/10.7289/V5C8276M) arcminute global relief model of the Earth's surface (https://www.ngdc.noaa.gov/mgg/global/) was used to generate bathymetry and the Global Self-consistent, Hierarchical, High-resolution Geography Database (GSHHG; https://www.ngdc.noaa.gov/mgg/shorelines/gshhs.html) was used to produce co-ordinates for a high-resolution coastline and both plotted using Matlab version 9.5 software (https://www.mathworks.com) with the M_Map mapping package (version $1.4 \mathrm{~m}$, created by R. Pawlowicz, https://www.eoas.ubc.ca/ rich/map.html); (b-d) the proportion of modeled particles released from each of the 6 areas closed to protect large-sized sponges (Source Areas; Areas 1, 2, 3, 4, 5, 6) and passing over or terminating in another area closed to protect large-size sponges (Receiving Areas). For each Receiving Area the percentage of the total number of particles released (from all source areas) are provided. Those values include particles that crossed, terminated or were retained in the Receiving Area. Drift durations were 2 weeks using average currents from the ocean model. Release depths were $1245 \mathrm{~m}, 1422 \mathrm{~m}$ and $1684 \mathrm{~m}$ respectively. 
in the forward-tracking model with only a small proportion of particles making the connection. However, the higher number of particles seeded in the back-tracking model allowed for identification of Area 2 as an important source of particles for Area 1 (Supplementary Fig. S2). It should be noted that Area 1 has a small spatial area, which is possibly one reason for the reported weak connectivity in the forward modeling; this closed area does not appear as a potential Source Area in the back-tracked models as there is no downstream closed area to act as a destination for particles released from Area 1 (Supplementary Fig. S2). Area 6, being the furthest upstream area in the network (Fig. 5a) is similarly unconnected as a Receiving Area in the forward-tracking models due to its position, and has only minimal retention in the deepest parts of the closure identified only in back-tracking models (Supplementary Table S1), making this area highly dependent on source populations from outside of the network (Fig. 4). The connectivity matrices were significantly correlated between Summer, Autumn and the Average backward-tracking models for all three depths with Pearson's r-values of 0.997-0.999, indicating statistically similar results across seasons and averaged models at each release depth.

Sea pens. The connectivity amongst areas closed to protect sea pens (Areas 2, 7-12, and 14) was assessed after 2-week, 1-month and 3-month durations, as there is no consensus on PLD for this group ${ }^{7}$. These eight areas are located in the shallower waters of the Flemish Cap. Strong connections appear to exist among Areas 10, 11 and 12 resulting from their spatially proximate locations (Fig. 6). The back-tracking model showed a very high proportion of the particles originating in Area 10 connecting to Area 11, under all depth/duration scenarios (Supplementary Fig. S3), while the forward-tracking model showed similarly high proportions of particles connecting between Area 12 and Area 10, at $643 \mathrm{~m}$ and $902 \mathrm{~m}$, with the latter being the Receiving Area (Fig. 6). A highly interconnected network operative was observed between Areas 7, 8 and 9 and Areas 10, 11 and 12 in both the back-tracked (Supplementary Fig. S3) and forward-tracked models (Fig. 6). As PLD increases to 1 month, connectivity appears to establish between more distant areas such as the connection from Areas 7, 8 and 9 with Area 2 (Fig. 6, Supplementary Fig. S3). After a 3-month PLD, long-term transportation may bring about the links from all the closed areas on Flemish Cap to Area 2 (Fig. 6, Supplementary Fig. S3). The currents are complex in this region with some particles displacing in a counterclockwise direction and clockwise in other locations. The minimum arrival time of particles making these connections was generally less than 1 month, while it may take more than 2 or 3 months for particles from Area 7 to reach Area 14 at $643 \mathrm{~m}$. The transit time distributions for these areas present obvious fluctuations, which arise from the relatively large number of closed areas in close proximity to one another (Supplementary Fig. S5; only scenarios for $643 \mathrm{~m} / 3$ month PLD shown). Particles are very likely to arrive at these areas within 20 days drift time. The number of connections decreased sharply with depth; the depth ranges of these areas are small and release depths were close to the maximum depths of the areas, limiting the range of potential movement in the vertical. Those connections that were made generally contained a high proportion of released particles (Fig. 6, Supplementary Fig. S3). This is particularly evident for the connections to Area 2 from areas on the top of Flemish Cap and contribute to a high degree of redundancy for the sea pen populations of Area 2 (Supplementary Table S2), which were strongest from the shallower release depths and 3 month drift duration (Fig. 6). Area 2 received between 5.77 and $23.47 \%$ of the total number of particles released (Fig. 6). Retention occurred at all potential spawning seasons (spring, summer and winter) and on average in five of the eight areas with 2 week drift duration and decreased with particle release depth (Supplementary Table S2). Area 2, the largest of the areas, showed consistent retention of particles across drift durations, and release depths and to some extent across seasons (Supplementary Table S2). As for the sponges, connectivity matrices were significantly correlated between Spring, Summer, Winter and the Average backward-tracking models for all three depths with Pearson's r-values ranging from 0.877 (643 m depth: Spring vs. Summer) to 0.999 , indicating statistically similar results across seasons and averaged models at each release depth and drift time duration.

Large Gorgonian corals. The connectivity amongst areas closed to protect large gorgonian corals (Areas 2, 4, 5 and 13) was assessed after 2-week, 1-month and 3-month PLD, as there is no consensus on larval duration for this group ${ }^{7}$. These areas evidenced a downstream clockwise connectivity in space at both 2-week and 1-month drift durations in the forward-tracking models (Fig. 7a,b, Supplementary Table S3) with the back-tracking models reinforcing downstream connectivity between Area 13 and Area 2 at $1245 \mathrm{~m}$ and $1684 \mathrm{~m}$ depths (Supplementary Fig. S4; Supplementary Table S3). There was some redundancy in Area 13 which receives particles from Areas 4 and 5 in both forward- and back-tracking models with the shorter drift duration and shallower particle release depths (Fig. 7, Supplementary Fig. S4, Supplementary Table S3). As the downstream closure, Area 2 demonstrated the greatest redundancy, receiving particles from all of the other areas (reaching a maximum of $12.74 \%$ of the total particles released in the forward-tracking model) (Fig. 7). This area also shows a degree of retention (Supplementary Table S3). However, the strongest connections were made between Area 5 and Area 4 with Area 4 receiving up to $22.90 \%$ of released particles from Area 5 in the forward-tracking models (including both retentions and particles passing over) and similarly high proportions under different drift duration and depth combinations (Fig. 7). Area 4 also demonstrated some retention of particles at the deeper release depth (Supplementary Table S3). The connection time between Area 5 and Area 4 peaks at approximately 5 days in both forward- and back-tracking modes at $643 \mathrm{~m}$ release depth (Supplementary Fig. S5), which may be too short for larval settlement.

Water mass characteristics of the closed areas. The bottom temperature and salinity data from EN4 profiles in each closed area were averaged from all 12 months in each year, and shaded areas in the plot show the range of the data in each area within that year (Supplementary Fig. S6). The cruise data are averaged in each closed area for the year the survey was carried out and represent an independent data source. Not surprisingly, 
a

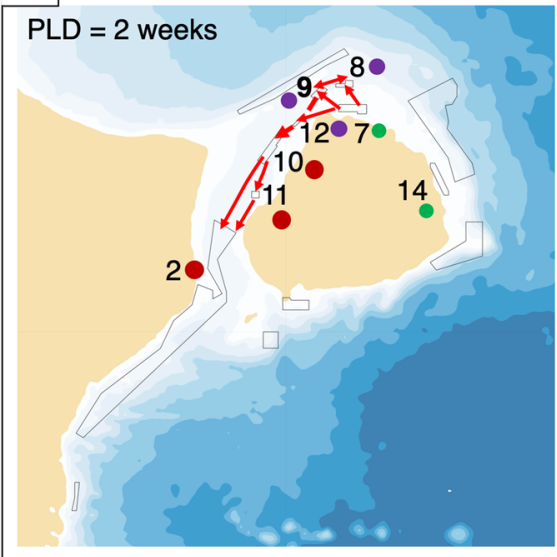

- Release depth $902 \mathrm{~m}$

PLD = 1 month

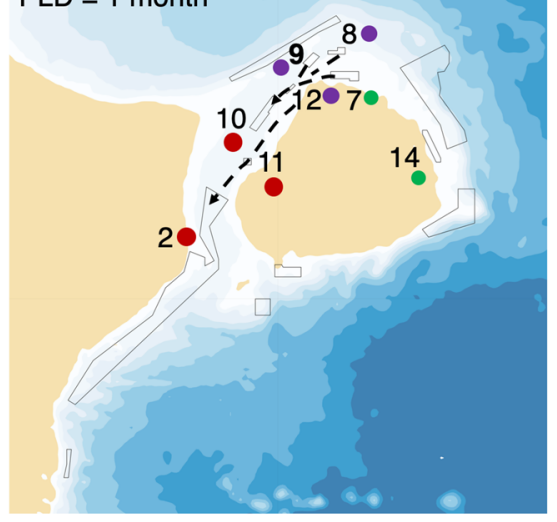

Release depth $1,062 \mathrm{~m}$

PLD $=3$ months

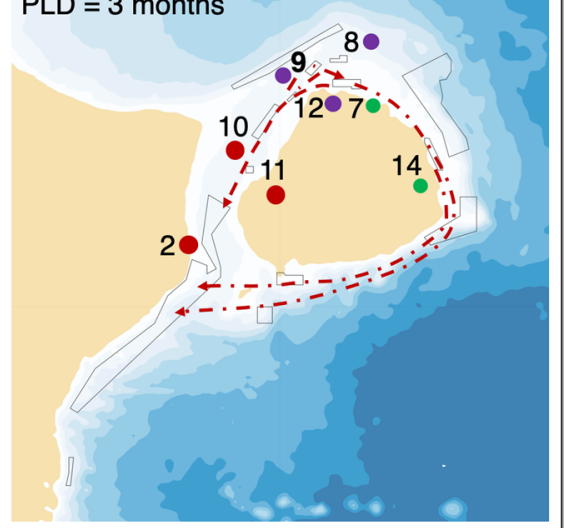

b 2-week duration at $643 \mathrm{~m}$ for

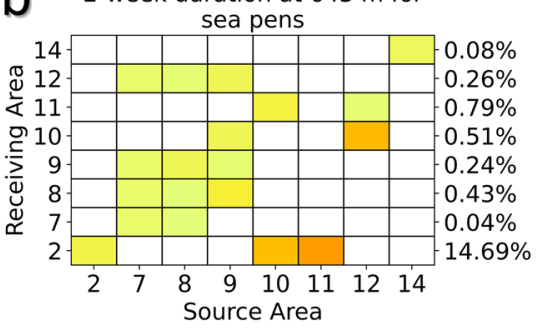

e 2-week duration at $902 \mathrm{~m}$ for

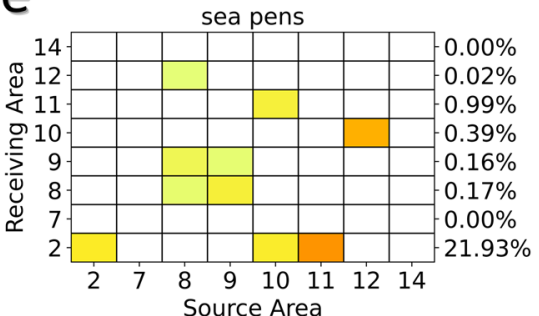

h 2-week duration at $1,062 \mathrm{~m}$

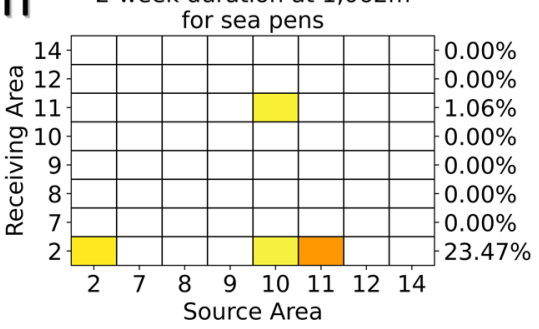

C 1-month duration at $643 \mathrm{~m}$

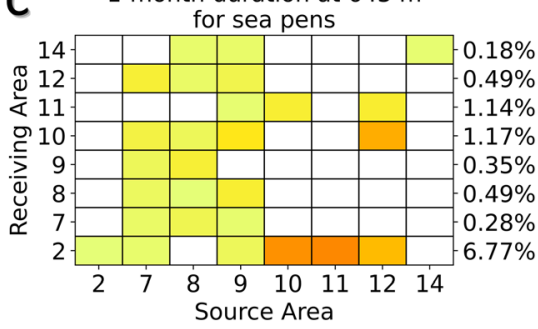

f

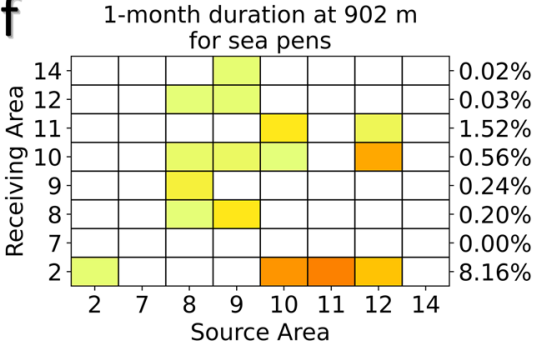

1 1-month duration at $1,062 \mathrm{~m}$
for sea pens

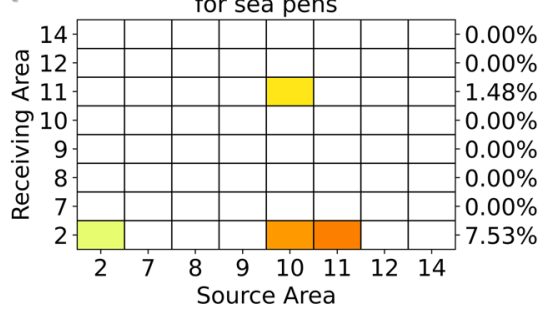

d 3-month duration at $643 \mathrm{~m}$ for sea pens

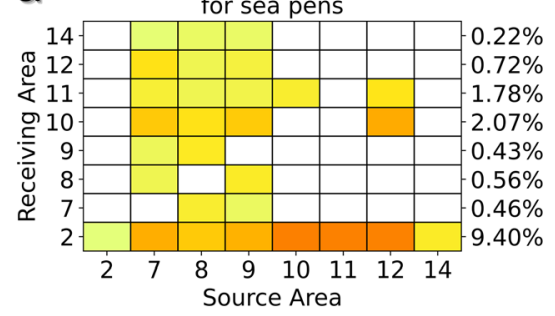

g 3-month duration at $902 \mathrm{~m}$ for

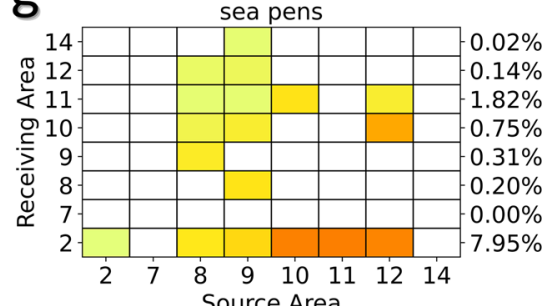
Source Area

j 3-month duration at $1,062 \mathrm{~m}$

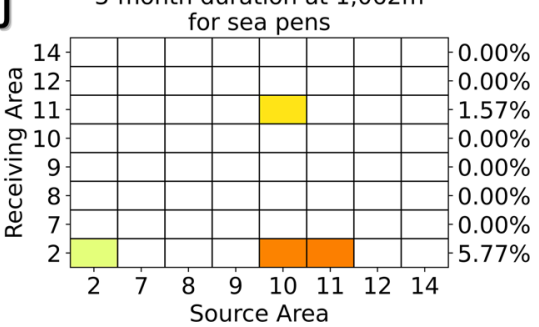

$\begin{array}{llllll}0.0 & 0.2 & 0.4 & 0.6 & 0.8 & 1.0\end{array}$

Proportion of particles crossing or terminating in another Closed Area

Figure 6. Functional connectivity among areas closed to protect sea pens. (a) Forward-tracking connectivity pathways for particles released at 3 depths in each of the 8 areas closed to protect sea pens (Areas 2, 7, 8, 9, 10,11,12,14). Drift durations were 2 weeks, 1 month, and 3 months. The closed circles near the number code of some of the closed areas denotes that particles from this area are only released at this depth due to the depth of the closure, and the line indicates where particles can reach another closed area when released from this depth. The maps were generated using bathymetry and coastline data produced and made publically available by the NOAA National Centers for Environmental Information (NCEI). The ETOPO1 Ice Surface (https://doi.org/10.7289/V5C8276M) arc-minute global relief model of the Earth's surface (https://www.ngdc.noaa.gov/mgg/global/) was used to generate bathymetry and the Global Self-consistent, Hierarchical, High-resolution Geography Database (GSHHG; https://www.ngdc.noaa.gov/mgg/shorelines/ gshhs.html) was used to produce co-ordinates for a high-resolution coastline and both plotted using Matlab version 9.5 software (https://www.mathworks.com) with the M_Map mapping package (version $1.4 \mathrm{~m}$, created by R. Pawlowicz, https://www.eoas.ubc.ca/ $\sim$ rich/map.html); (b-j) The proportion of modeled particles released from each of the 8 areas closed to protect sea pens (Source Areas; Areas $2,7,8,9,10,11,12,14$ ) and passing over or terminating in another area closed to protect sea pens (Receiving Areas). For each Receiving Area the percentage of the total number of particles released (from all Source Areas) are provided. Those values include particles that crossed, terminated or were retained in the Receiving Area. Particle release depths were $643 \mathrm{~m}(\mathbf{b}-\mathbf{d}), 902 \mathrm{~m}(\mathbf{e}-\mathbf{g})$ and $1062 \mathrm{~m}(\mathbf{h}-\mathbf{j})$ with drift durations of 2 weeks $(\mathbf{b}, \mathbf{e}, \mathbf{h}), 1$ month $(\mathbf{c}, \mathbf{f}, \mathbf{i})$, and 3 months $(\mathbf{d}, \mathbf{g}, \mathbf{j})$. 


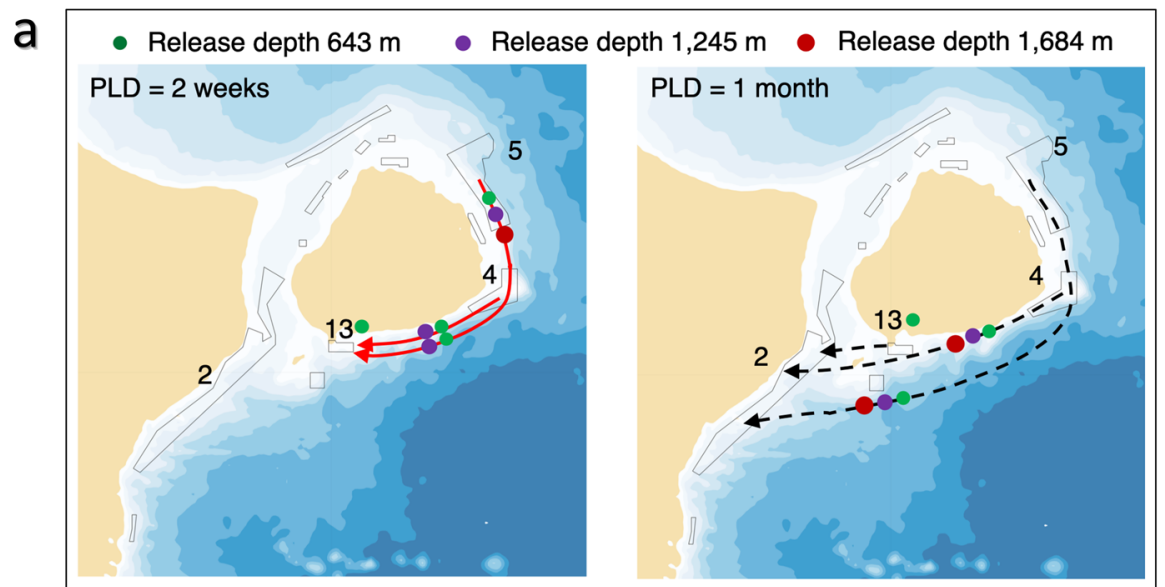

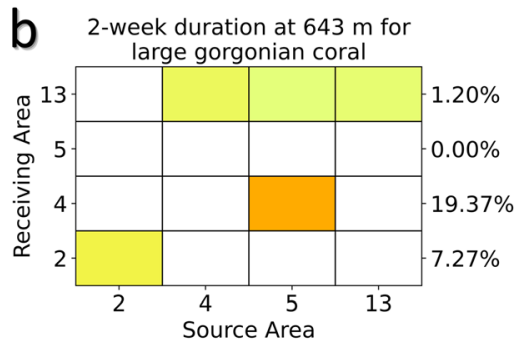

e 2-week duration at 1,245 m
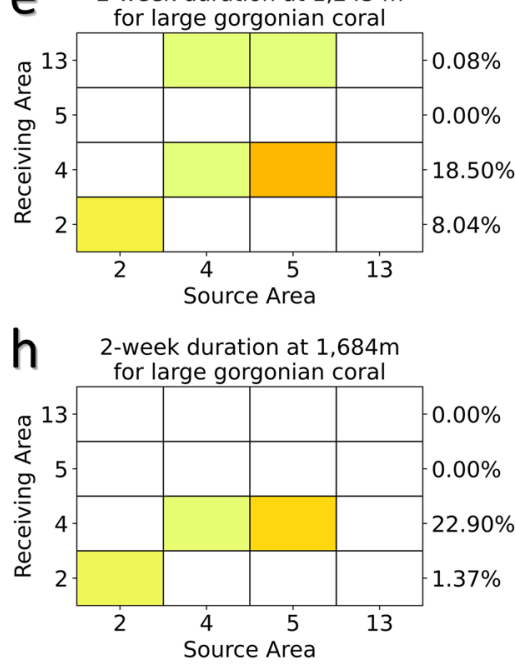

C 1-month duration at $643 \mathrm{~m}$

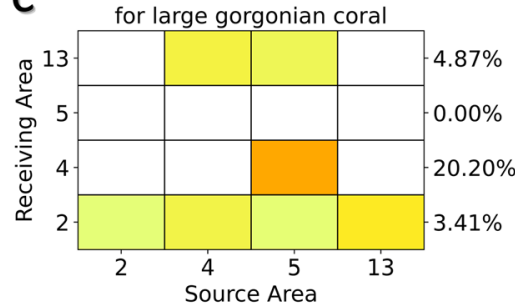

f

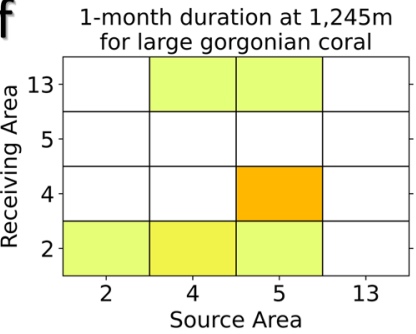

i

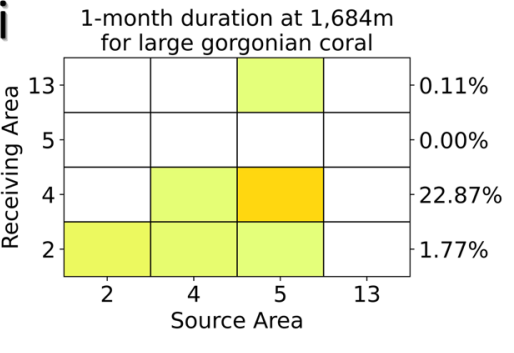

$0.35 \%$ $0.00 \%$

$18.60 \%$ $2.98 \%$

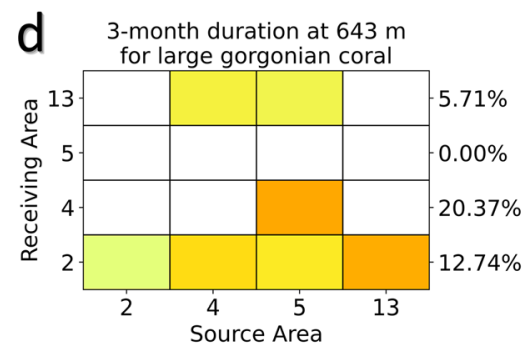

g 3-month duration at $1,245 \mathrm{~m}$
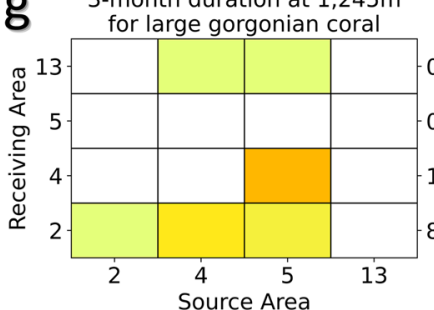

$-0.35 \%$
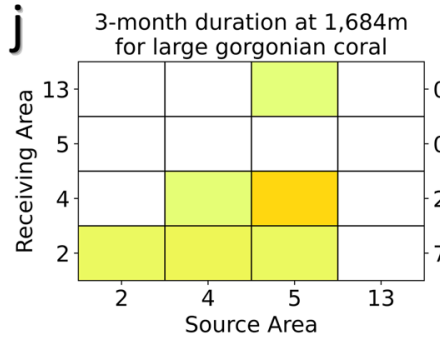

$0.11 \%$

$0.00 \%$

$-22.90 \%$

$\begin{array}{llllll}0.0 & 0.2 & 0.4 & 0.6 & 0.8 & 1.0\end{array}$

Proportion of particles crossing or terminating in another Closed Area

Figure 7. Functional connectivity among areas closed to protect large Gorgonian corals. (a) Forward-tracking connectivity pathways for particles released at 3 depths in each of the 4 areas closed to protect large gorgonian corals (Areas 2, 4, 5, 13). Drift durations shown are 2 weeks and 1 month. The connectivity map with 3-month drift duration is not shown because it is the same as that of 1-month drift duration. The closed circles near the number code of some of the closed areas denotes that particles from this area are only released at this depth due to the limitation of maximum depth, and the closed circles over the lines indicates particles can reach another closed area when released from this depth. The maps were generated using bathymetry and coastline data produced and made publically available by the NOAA National Centers for Environmental Information (NCEI). The ETOPO1 Ice Surface (https://doi. org/10.7289/V5C8276M) arc-minute global relief model of the Earth's surface (https://www.ngdc.noaa.gov/mgg/global/) was used to generate bathymetry and the Global Self-consistent, Hierarchical, High-resolution Geography Database (GSHHG; https://www.ngdc. noaa.gov/mgg/shorelines/gshhs.html) was used to produce co-ordinates for a high-resolution coastline and both plotted using Matlab version 9.5 software (https://www.mathworks.com) with the M_Map mapping package (version $1.4 \mathrm{~m}$, created by R. Pawlowicz, https://www.eoas.ubc.ca/ rich/map.html); (b-j) The proportion of modeled particles released from each of the 4 areas closed to protect large gorgonian corals (Source Areas; Areas 2, 4, 5, 13) and passing over or terminating in another area closed to protect large gorgonian corals (Receiving Areas). For each Receiving Area the percentage of the total number of particles released (from all Source Areas) are provided. Those values include particles that crossed, terminated or were retained in the Receiving Area. Particle release depths were $643 \mathrm{~m}(\mathbf{b}-\mathbf{d}), 1245 \mathrm{~m}(\mathbf{e}-\mathbf{g})$ and $1684 \mathrm{~m}(\mathbf{h}-\mathbf{j})$ with drift durations of 2 weeks $(\mathbf{b}, \mathbf{e}, \mathbf{h}), 1$ month $(\mathbf{c}, \mathbf{f}, \mathbf{i})$, and 3 months $(\mathbf{d}, \mathbf{g}, \mathbf{j})$. 
except for Area 12, the EN4 temperatures in all other six closed areas were $\sim 1{ }^{\circ} \mathrm{C}$ lower than the cruise data. The coarse resolutions in horizontal and vertical spaces are likely the cause for this discrepancy. EN4 salinities were generally saltier than those reported from the cruise surveys. Though some discrepancy does exist, the EN4 data provide an opportunity to investigate the potential variability of temperature and salinity in each closed area. All fourteen areas had relatively stable salinity or temperature for the 1975-2017 period (Supplementary Fig. S6). The average bottom temperatures in these areas were all below $4{ }^{\circ} \mathrm{C}$, with average salinity above 34.8 on the practical salinity scale (Supplementary Fig. S6), the reference value to calculate freshwater content/transport in many studies ${ }^{25}$. Areas $1-6,10$ and 14 were on average colder (below $3^{\circ} \mathrm{C}$ ) than Areas 7-9, 11-13, while salinity differed less between areas. We conclude that the epibenthic invertebrate species in these closed areas reside in a stable, cold and salty environment. Particles released from each of the closed areas and back-tracked for a period of 3 months also experienced stable temperature and salinity conditions over their pathways (not shown). Such particles released from Area 5 showed the greatest temperature variation in the standard deviation of the temperature along the pathway $\left(<0.31^{\circ} \mathrm{C}\right)$, while Area 2 showed the greatest salinity variation (standard deviation $<0.054 \mathrm{PSU}$ ); all mean values of temperature and salinity were constant over the duration (not shown).

\section{Discussion}

Connectivity models are emerging as a useful tool for studies in the deep ocean (e.g., $\left.{ }^{7,26}\right)$. However, their use, and by extension depiction of reality, relies upon the use of appropriate hydrodynamic models, a good understanding of the oceanographic conditions within the model domain, adequate testing of model parameters, and some knowledge of larval release and behavior. In this study, we extended earlier work ${ }^{7,20}$ by integrating a more complex larval dispersal model with a regional-scale hydrodynamic model capable of simulating 3-D particle movement. Ultimately, we observed enhanced connectivity among the NAFO closed areas and documented the potential for strong vertical displacement (Fig. 8) at release depths greater than $450 \mathrm{~m}$ (Figs. 2, 3) which encompassed the minimum depth of the closed areas to protect vulnerable species, that ranged from 483 to $2754 \mathrm{~m}^{7}$.

Comparison with previous studies in the region. LPT models have previously been produced for the Flemish Cap region using two combinations of tracking and ocean models ${ }^{7,20}$. Model outputs from Parcels and $\mathrm{BNAM}^{20}$ and those generated with WebDrogue and the Quoddy ocean model ${ }^{7}$ were examined using like-forlike comparisons in 2-D applications ${ }^{20}$. Parcels/BNAM showed higher connectivity among the closed areas and a broader range of potential source areas than WebDrogue/Quoddy ${ }^{20}$. Such differences arise, in part, from the parameters used in the simulation, for example, greater number of simulated particles seeded in the Parcels/ BNAM scenarios, their foundation in annual-mean currents and the incorporation of random walk. However, even when these factors were eliminated, differences still remained, suggesting that the underlying hydrodynamic models drive the differences in outputs ${ }^{20}$. Differences between ocean models are to be expected, as many aspects of these models can vary, including numerical methods, grid structure, resolution (horizontal and vertical) and parameterizations of unresolved physical processes.

In this case, investigation showed that the observed differences can be explained by higher velocities in BNAM, which resulted in particle drifts calculated by Parcels following the same general tracks as those produced with WebDrogue and Quoddy but moving further ${ }^{20}$. Parcels and WebDrogue both track particles based on the same kinematics formula:

$$
\mathrm{x}_{\mathrm{t}}=\int_{t_{0}}^{t_{1}} v d t+\mathrm{x}_{0}
$$

Thus, in the 2-D simulations compared ${ }^{20}$, it was concluded that any difference in the calculated position $\left(\mathrm{x}_{\mathrm{t}}\right)$ for a given time $(t)$ and release position $\left(\mathrm{x}_{0}\right)$ must be caused by differences in the velocities $(v)$ imported from the ocean models (BNAM and Quoddy respectively).

BNAM and Quoddy belong to different families of ocean models. BNAM uses horizontally-structured grids, whereas Quoddy uses horizontally-unstructured grids. Wang et al. ${ }^{27}$ have compared surface currents derived from BNAM with mapped currents derived from surface-drifter data, finding strong correlation, which suggests that the BNAM model's outputs are realistic for the region of interest here, at least for surface waters. We suggest that the connectivity patterns determined with Parcels herein, should be considered to better represent reality in the region around Flemish Cap in part due to this support from independent data but also due to the incorporation of vertical displacement through the use of the 3-D modeling, which is shown to potentially have a large influence on the LPT outputs for this region (Figs. 2, 3, 8).

Physical oceanographic characteristics in the region. Lazier and Wright ${ }^{28}$ report the presence of a deeper extension of the Labrador Current which they call the "Deep Labrador Current" (DLC). Hall et al. ${ }^{29}$ show this as a possibly separate branch of the current reaching depths below $1000 \mathrm{~m}$. Farther offshore, intensified toward the bottom layer, there is the Deep Western Boundary Current (DWBC), a dominant feature in the bottom layer between 2500 and $3500 \mathrm{~m}$ water depth. While some of the closed areas reach the influence of the DWBC, most lie at intermediate depths where the DLC predominates, and controls the connectivity among the NAFO closed areas in the Flemish Cap region. Biophysical connectivity patterns for large-sized sponges and large gorgonian corals show strong downstream interdependence with upstream closed areas on the DLC path acting as source populations for adjacent downstream closed areas. In some cases, with longer drift durations, this downstream connectivity confers redundancy on some areas. Area 2, the largest of the closed areas and recipient of water from both branches of the $\mathrm{DLC}^{30,31}$ (the branch through Flemish Pass and the branch rounding Flemish Cap) has the greatest redundancy and shows retention due to its larger size. We know that size is a 


\section{a Depth: $100 \mathrm{~m}$}

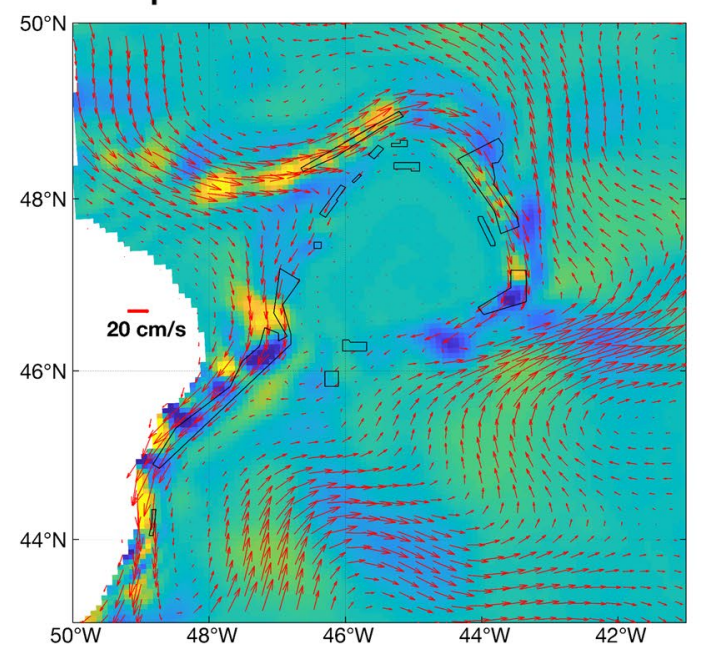

\section{b Depth: 1,000 m}

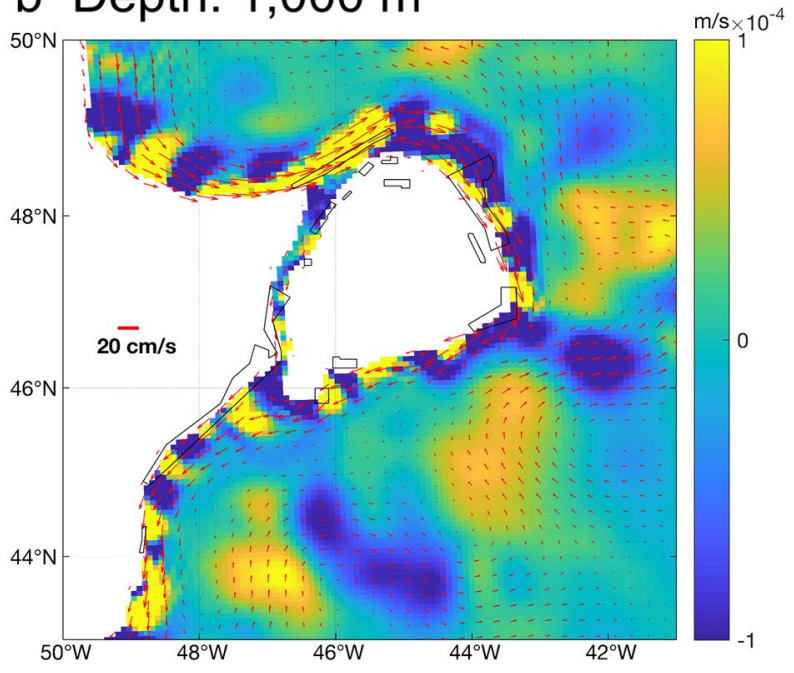

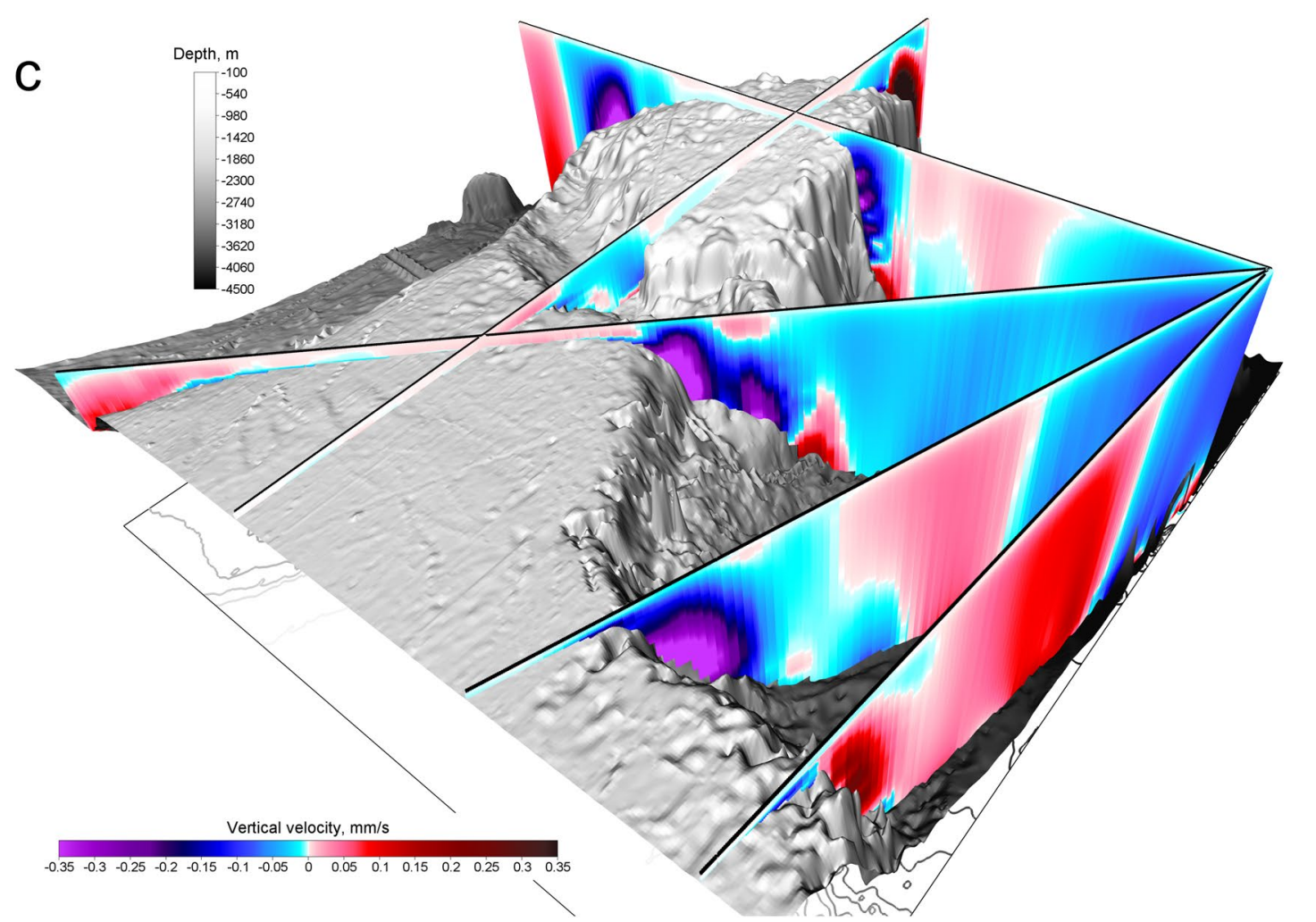

Figure 8. Distributions of horizontal velocity vectors $(\mathrm{cm} / \mathrm{s})$ and vertical velocity contours $\left(\mathrm{m} / \mathrm{s} \times 10^{-4}\right)$. $($ a) $100 \mathrm{~m}$ and (b) $1000 \mathrm{~m}$ depth in the Flemish Cap area of the northwest Atlantic. Positive (yellow) and negative (blue) values denote upward and downward velocity respectively. (c) Vertical velocity slices showing areas of upward (reds) and downward (purples) velocity. The areas closed by NAFO to protect deep-sea sponges, corals and sea pens are outlined in black in $(\mathbf{a}, \mathbf{b})$. All data were derived from the BNAM oceanographic model. The maps in (a,b) were generated using bathymetry and coastline data produced and made publically available by the NOAA National Centers for Environmental Information (NCEI). The ETOPO1 Ice Surface (https://doi. org/10.7289/V5C8276M) arc-minute global relief model of the Earth's surface (https://www.ngdc.noaa.gov/ $\mathrm{mgg} / \mathrm{global} /$ ) was used to generate bathymetry and the Global Self-consistent, Hierarchical, High-resolution Geography Database (GSHHG; https://www.ngdc.noaa.gov/mgg/shorelines/gshhs.html) was used to produce co-ordinates for a high-resolution coastline and both plotted using Matlab version 9.5 software (https://www. mathworks.com ) with the M_Map mapping package (version $1.4 \mathrm{~m}$, created by R. Pawlowicz, https://www. eoas.ubc.ca/ rich/map.html). The 3-D map in $8 \mathrm{c}$ was generated using the ETOPO1 Ice Surface bathymetry and plotted with Voxler software (https://www.goldensoftware.com/products/voxler). 
factor here as Area 1, which is downstream of Area 1 and an order of magnitude smaller in size (Supplementary Table S5) shows no redundancy and minimal retention (Supplementary Table S1). For sea pens, in the shallower waters of Flemish Cap ( till $>578 \mathrm{~m}$ ), we were able to detect connectivity among several small closed areas (Areas $7,8,9,10,11$ and 12) using both forward- and back-tracking models, that was influenced by an area where some RAFOS floats ballasted for $700 \mathrm{~m}$ reversed their clock-wise direction and travelled west through Flemish Pass ${ }^{32}$.

Our models also showed large downward vertical velocities in the deep waters below $1000 \mathrm{~m}$ of the continental slopes surrounding Flemish Cap and the Tail of Grand Bank (Fig. 8), which has significant implications for the benthic invertebrate fauna in this region. Current distributions at depths of $100 \mathrm{~m}$ and $1000 \mathrm{~m}$, with horizontal velocity vectors and vertical velocity contours (Fig. 8) revealed a prevalent downward vertical velocity around Flemish Cap, with alternating areas of upward and downward velocity along the continental slope. From the horizontal velocity vectors at the two depths in the southeast of Flemish Cap (Fig. 8a,b), it is clear that the current there is dominated by the NAC in shallow water, while this situation changes in deep water and becomes DLCdominated current. These vertical velocity maps could be used in species distribution models as environmental layers to determine their importance as habitat predictors.

Vertical velocity slices indicate that the downward velocity occurs in the upper slope areas with upward velocity in the deeper slope and offshore areas with implications for the downslope transport of organisms and nutrients from upper layers and recycling of nutrients from the deep waters. At $1000 \mathrm{~m}$ and deeper, vertical displacements are strong mainly due to these downward vertical velocities, and also the strong DLC along the slope. Moorings placed on Sackville Spur, Flemish Cap (Area 6) have shown that the DLC follows along isobaths between water depths of $\sim 1200$ and $2200 \mathrm{~m}$ in that area ${ }^{32}$. The pattern was less strong but still evident at the surface, 100 and $450 \mathrm{~m}$ (Fig. 8) suggesting a mechanism for vertical transport of food from the more productive surface waters to the deep sea (e.g. $\left.{ }^{14}\right)$. Such linkages have been demonstrated in numerous areas within the North Atlantic and have been suggested as being largely responsible for fuelling productive and diverse deep-sea ecosystems such as those containing corals and sponges ${ }^{4}$. In addition to food supply, the prominent downward vertical velocities and strong horizontal currents likely create a barrier to active larval movement to the surface from release sites on the seafloor. This adds to the several water mass layers previously described as potential barriers to larval movement from the closed areas put in place by $\mathrm{NAFO}^{7}$. Further, the strong baroclinic northeastward NAC mainly impacts these top layers, and the impacts of this current on the particle dispersals at the surface layer are significant, carrying the particles away from the Flemish Cap area ${ }^{27}$.

The DLC has been found to have significant inter-annual variability, and a weakening trend has existed for the past 20 years $^{33}$; the weakening trend is probably linked to increasing heat content in the Labrador Sea due to weakening in winter atmospheric cooling over the past three decades ${ }^{19,34}$. The changes in the benthic layer over the Labrador Sea slope (at about $1000 \mathrm{~m}$ water depth) are found to be highly correlated with the changes in the heat content of the entire $2000 \mathrm{~m}$ top layer in the Labrador Sea. These and similar long-term changes in the DLC spreading along the Labrador slope are likely to have significant consequences for the connectivity of benthic bathyal fauna in this region ${ }^{20}$, as demonstrated here.

The interpolated EN4 data showed that all of the closed areas have maintained a stable environment over past decades, where the conditions contribute to the establishment and survival of the protected species. It may also indicate that the species are less likely to adapt to climate change due to a potential requirement for habitat stability. If bottom temperature increases in the future, which is a very high likelihood for this region, it could affect species distributions ${ }^{21}$. Morato et al..$^{21}$ predicted shifts in the distribution of selected deep-sea species in the North Atlantic, including that of two large gorgonian corals that occur in the Flemish Cap region, Acanthogorgia armata and Paragorgia arborea, which were induced by future (2081-2100) climate change based on the current (1951-2000) environmental conditions. They found that both species are predicted to lose $>80 \%$ of their habitat, with Paragorgia arborea showing near extinction of suitable habitat (99\%). The present-day temperature data collected for the basin-scale distribution of these species was $4.92 \pm 2.21^{\circ} \mathrm{C}$ for A. armata and $3.87 \pm 2.26^{\circ} \mathrm{C}$ for P. arborea, which is slightly warmer than the EN4 data from Areas 2, 4, 5 and 13 (Supplementary Fig. S6) but consistent with observational data from the cruises which are slightly elevated above EN4. Projection of bottom temperatures to above $5^{\circ} \mathrm{C}$ in this region by $2081-2100$ (average \pm standard deviation of $4.169 \pm 0.657^{\circ} \mathrm{C}$ from $1951-2000$ to $5.794 \pm 1.152^{\circ} \mathrm{C}$ by $2081-2100^{21}$ ) would require a greater acclimation for $P$. arborea than it has experienced over recent decades, with corals in Area 13 perhaps being best adapted to the projected warming due to the present and historical warmer bottom temperatures there (Supplementary Fig. S6).

In conclusion, 3-D LPT simulations for the Flemish Cap region have shown enhanced connectivity over 2-D models and unexpected, current-driven, strong (up to $1000 \mathrm{~m}+$ ) potential for downward displacement at depth $(>450 \mathrm{~m}$ to $2250 \mathrm{~m})$. The area closures in this region selected to protect vulnerable marine species are all at depths greater than $450 \mathrm{~m}$. Despite a general lack of knowledge of larval duration and behaviour of these species ${ }^{7}$ pre- $^{-}$ venting further, more specific incorporation of particle behaviour into our study, our results indicate that there are even greater barriers to surface movements of larvae released from the sea bed at depth than had previously been found ${ }^{7}$ due to downwelling at depth. High correlations between seasonal connectivity patterns suggest that the lack of information on spawning time for many of the coral and sponge species, is unlikely to change these results substantively. The current velocities create down-stream interdependence among closed areas and allow redundancy to develop in some of the areas of the network, with some of the larger areas showing retention as well as redundancy (e.g., Areas 2 and 4). At the same time, source populations for sponges in the upstream closed area (Area 6) are likely in adjacent waters of the Canadian continental shelf where additional sponge grounds are predicted to occur ${ }^{10}$. Potential sources for sponge larvae drifting into Area 6 (Fig. 4) have been identified as coming from the Northeast Newfoundland Slope Closure, a $55,353 \mathrm{~km}^{2}$ Canadian marine refuge put in place to protect corals and sponges on the continental slope from all bottom contact fishing activities (https://www.dfompo.gc.ca/oceans/oeabcm-amcepz/refuges/northeastnewfoundlandslope-talusnordestdeterreneuve-eng.html). This Canadian marine refuge may support the sponge populations in the high-seas NAFO area of Flemish Cap. 
Collectively this information can be used to inform management decisions related to the size and placement of these closed areas, and demonstrates the added value connectivity modeling can bring in building redundancy into MPA network design, even across political boundaries. Identification of areas of upward and downward velocity (Fig. 8) have potential for use in species distribution modeling as predictors of habitat suitability.

\section{Methods}

Lagrangian particle simulation. The Parcels framework version 2.1 (https://www.oceanparcels.org ${ }^{9,35}$ ) was used to perform three-dimensional (3-D) passive particle tracking experiments in the northwest Atlantic. Climatological monthly-mean currents were obtained from the Bedford Institute of Oceanography North Atlantic Model (BNAM) 27,33,36,37 ocean model over the period 1990-2015. BNAM is an eddy resolving North Atlantic Ocean model with a nominal resolution of $1 / 12^{\circ}$ (approximately $\sim 8 \mathrm{~km}$ at the Equator). It is based on NEMO 2.3 (Nucleus for European Modelling of the Ocean) and has a maximum of 50 levels in the vertical, with level thickness increasing from $1 \mathrm{~m}$ at the surface to $200 \mathrm{~m}$ at a depth of $1250 \mathrm{~m}$ and reaching the maximum thickness of $460 \mathrm{~m}$ at the bottom of the deep basins (approximately $5730 \mathrm{~m}$ ). BNAM uses partial cell for the bottom layer, which improves the representation of the bottom layer.

We advected Lagrangian particles using the fourth-order Runge-Kutta method as the integration scheme with a time step of $20 \mathrm{~min}$, and a horizontal mixing of $100 \mathrm{~m}^{2} \mathrm{~s}^{-19}$. Optimal parameters for the number of particles, and particle spacing were determined to minimize computational time without introducing bias ${ }^{20}$. A single 20 min. time step was chosen for releasing and following particle trajectories to ensure that particles do not cross the grid in a single time step. Horizontal diffusion in the study region previously has been reported as $50^{38}, 64^{39}$ and 150 $\mathrm{m}^{2} \mathrm{~s}^{-140}$ and the spatial distribution of modeled particles did not differ markedly with applications of 100 and 200 $\mathrm{m}^{2} \mathrm{~s}^{-120}$. Particle spacing of $0.01^{\circ}$ was generally employed ${ }^{20}$ except for the calculation of back-tracked transit time distributions for the assessment of functional connectivity, where a finer spacing of $0.005^{\circ}$ was used to allow more particles to be both released, and thus to enter the closed areas with smaller spatial size (e.g., Areas 7-9). Particles were removed from the simulation if they reached the boundary of the modeled spatial domain, delineated by the marine area bounded by the $31.4^{\circ}$ and $73.9^{\circ} \mathrm{W}$ meridians and by the $40.8^{\circ}$ and $70.5^{\circ} \mathrm{N}$ parallels of latitude.

Simulation experiments. Our experiments simulated larval transport and determined how temporal and spatial ocean current changes affect dispersal. We performed three different simulation experiments aimed at determining different aspects of physical connectivity among NAFO closed areas (Fig. 1, Supplementary Table S4). Within each experiment we ran a number of scenarios evaluating different depths, northern hemisphere seasons (through extraction of associated ocean model data) and drift-time durations (Supplementary Table S4). Season and drift-time duration were based on a previous review of the life-history characteristics of the coral, sponge and sea pen species that are protected by the closures ${ }^{7}$ and allow model outputs to be interpreted as biophysical models for the assessment of functional connectivity. Parcels allows for larval behaviour to be incorporated into the tracking model (e.g., swimming, vertical movements), however, very little is known about the reproductive biology of the deep-sea species protected by the closed areas ${ }^{7}$. Consequently, we consider larvae as passive objects in order to reduce uncertainties, as such behavior is difficult to quantify and validate ${ }^{41}$ and the larvae of many deep-sea species have not been observed in situ.

Vertical movements in 3-D models. The upward and downward movement of forward-tracking particles released from each of the 14 closed areas was evaluated at each of 5 depths for 3 drift durations using average and seasonal monthly-mean currents from BNAM (Supplementary Table S4). Particle spacing of $0.01^{\circ}$ was employed for particle seeding ${ }^{20}$. Particles were seeded uniformly (total number of particles in brackets) at the surface (14,909), $100 \mathrm{~m}(14,909), 450 \mathrm{~m}(14,877), 1000 \mathrm{~m}(11,399)$ and $2250 \mathrm{~m}$ (1308) depths, over all of the closed areas at the initial time point, and then tracked forward under each drift duration scenario ( 2 weeks, 1 month and 3 months). Because the closed areas differ in surface area with the increase in depth, the number of simulated particles released in each area varied and decreased in deep water with the same uniform particle spacing. The depths were chosen such that the maximum arrival depth of the first run became the approximate particle release depth for the subsequent run. From each particle trajectory, the following were recorded: (1) maximum and minimum depths trajected to by each particle for each release depth; (2) considering the randomness of particle motion, depths reached by the first $25 \%, 50 \%$ and $75 \%$ of particles were recorded. In a final simulation, the impact of seasons was investigated by seeding particles at depths of surface, $100 \mathrm{~m}, 450 \mathrm{~m}, 1000 \mathrm{~m}$ and $2250 \mathrm{~m}$ across four northern hemisphere seasons, and the average depth of $50 \%$ of sorted results recorded.

Potential source populations. For the purpose of identifying possible species source populations for those found inside the closed areas, both forward- and back-tracking simulations were utilized. Wang et al. ${ }^{20}$ has shown that the results from forward-tracking particles in this region are nearly identical to those produced through backtracking from the closed areas. Our experiments were run in 3-D under each of three different drift scenarios (2 weeks, 1 month and 3 months) with data extracted from an averaged (no seasonality) BNAM ocean model with particles released at $1000 \mathrm{~m}$ depth, which approximated the mean depth across all closed areas (Supplementary Table S5). Particle spacing of $0.01^{\circ}$ was employed for seeding ${ }^{20}$. For forward-tracking, 927,621 particles at $1000 \mathrm{~m}$ depth were seeded uniformly over the entire model domain at the initial time, and then forward-tracked under each drift duration scenario. For back-tracking, 11,417 particles at $1000 \mathrm{~m}$ depth were seeded uniformly over each of the closed areas (Fig. 1c) at the initial time, and then back-tracked under each drift duration scenario. Particles whose trajectory ended in or passed over a closed area were retained, and their initial positions binned and counted on a $0.1^{\circ} \times 0.1^{\circ}$ grid. 
Functional connectivity of sponges, sea pens and large Gorgonian corals. Six of the 14 closed areas (Areas 1-6) in the NAFO regulatory area on Flemish Cap and the Tail of Grand Bank (Fig. 1) were put in place to protect sponge ground ecosystems from significant adverse impacts of bottom contact fishing. These assemblages live at depths from 700 to $1400 \mathrm{~m}$ on the deep slopes of Flemish Cap and Grand Bank ${ }^{42}$. All known sponge larvae are lecithotrophic, and they are unable to capture food from their surroundings, therefore they are not expected to swim to surface waters to feed. Sponge larvae are capable of actively swimming but most of the time they are thought to rest in a vertical position and drift passively with the water current ${ }^{24}$. A large majority of larvae were found to stay around the parental habitat in the demersal water layer ${ }^{43,44}$, and in our models, we released particles from the seabed of each of the six closed areas.

Eight of the 14 closed areas (Areas 2,7-12 and 14) were closed to protect sea pens in the relatively shallower waters of Flemish Cap, with the species forming a distinct community on sandy and silt bottoms in the study $\mathrm{area}^{42}$. There is some information on the spawning season for some species or their congeneric representatives ${ }^{7}$ but in general little is known about the reproductive biology of the 13 sea pen VME indicator taxa known to occur on Flemish $\mathrm{Cap}^{45}$. Areas 2, 4, 5 and 13 provide conservation and protection for large gorgonian corals with at least 14 shallow- and deep-water species occurring in the study area ${ }^{45}$. Nothing is known of the pelagic larval duration (PLD) or the vertical position in the water column for these sea pen larvae or for the larvae of the large gorgonian corals. Three different durations ( 2 weeks, 1 month and 3 months) were considered to encompass all likely scenarios ${ }^{7}$.

Functional 3-D connectivity among closed areas containing specific deep-sea species was assessed with a PLD of 2 weeks, 1 month and 3 months using averaged and seasonal monthly-mean currents from BNAM (Supplementary Table S4). Particles were released at depths that reflected the on-bottom depths for each closed area for those areas designed to protect the same species (Supplementary Tables S5, S6). The minimum, middle and maximum depths of the mean depth ranges for the combined areas determined particle release depths (Supplementary Tables S5, S6). For all scenarios, the total number of released particles were initiated inside one of the closed areas (uniformly positioned) and the models run under each scenario in both forward and backward modes. The forward models used the $0.01^{\circ}$ particle spacing. By uniformly seeding all of the closed areas at a finer grid size $\left(0.005^{\circ}\right.$, see Lagrangian Particle Simulation above) and running back-tracking models, potential sources in the network of other closed areas could be identified for all closed areas except for Area 1, which had no downstream closed area to receive from. Supplementary Table S6 shows the particle numbers released for the models run for sponges, sea pens and large gorgonian corals at different depths.

To quantify connectivity based on forward- and backward-tracking particle trajectories the percentage of particles passing over and/or terminating within a closed area, including retentions (particles terminating in the area they were released from), were calculated ${ }^{46}$. For backtracked models only, we calculated Pearson's $r$ correlation coefficient to statistically compare the numbers of particles passing over or terminating in each closed area for seasonal and averaged oceanographic models. This was only done for the sponges and the sea pens, where biological information on spawning season was inferred, and hence called for seasonal models to be developed. No information on spawning time of the large gorgonian corals in the region was available to justify application of seasonal models for that functional group.

For both forward- and back-tracking models we also calculated the transit time distribution (TTD) ${ }^{47}$ which shows the number of days it takes for each particle to arrive in each closed area (excluding retentions), creating a histogram of arrival times. The data were then normalized by the total number of particles arriving in each area $^{48}$. To be able to directly compare TTD for both forward- and back-tracking models, we applied the same particle spacing of 0.005 degrees and a $20 \mathrm{~min}$. time step. Considering the limited pelagic larval duration for the coral and sponge species in this area ${ }^{7}$, in general, the faster that particles reach an area we assume a higher probability of successful settlement due to higher survivorship of larvae, provided that there is sufficient time for metamorphosis to occur. The percentage of particles passing over a closed area reflects the quantity of particles that reach the area, and the larger this proportion, we assume a greater the likelihood for the species to successfully recruit to the next generation.

Water mass characteristics of the closed areas. The water mass characteristics for each of the closed areas can be used to identify water masses influencing the benthic species and provide insight into their physiological niche. Temperature and salinity data from 1975 to 2017 from EN4 (https://www.metoffice.gov.uk/ hadobs/en $4 /{ }^{49}$ ) were used to examine bottom water mass characteristics for the investigated 14 NAFO closed areas (Fig. 1). In addition, the temperature and salinity values extracted from the back-tracked connectivity pathways from the BNAM model were examined for stability over the drift duration. Original data sources of EN4 include the World Ocean Database $\left(\mathrm{WOD}^{50}\right)$, the Global Temperature-Salinity Profile Programme (from 1990), and ARGO profiling data. The data were objectively analyzed onto a $1^{\circ}$ grid with 42 vertical levels for each month. Those data were linearly interpolated onto a $0.03^{\circ}$ grid for the Flemish Cap region with temperature and salinity values extracted for each of the 14 areas (Fig. 1). Observational temperature and salinity data (CTD and/ or SBE39) from scientific cruise surveys conducted by the Bedford Institute of Oceanography (BIO) from the closed areas were used to validate the interpolated EN4 data in closed Areas, 2, 3, 4, 5, 6, 10 and 12.

\section{Data availability}

Lagrangian particle simulator (Parcels) is freely available at https://www.oceanparcels.org. EN4 dataset for temperature and salinity from 1975 to 2017 can be obtained from the website https://www.metoffice.gov.uk/hadobs/ en $4 / ;$ climatological monthly-mean currents from BNAM and vertical velocity layers (Fig. 8a,b) are available on Mendeley Data ${ }^{51}$. 
Received: 22 April 2020; Accepted: 30 October 2020

Published online: 08 December 2020

\section{References}

1. Dullo, W. C., Flögel, S. \& Rüggeberg, A. Cold-water coral growth in relation to the hydrography of the Celtic and Nordic European continental margin. Mar. Ecol. Prog. Ser. 371, 165-176 (2008).

2. Puerta, P. et al. Influence of water masses on the biodiversity and biogeography of deep-sea benthic ecosystems in the North Atlantic. Front. Mar. Sci. 7, 239. https://doi.org/10.3389/fmars.2020.00239 (2020).

3. Davies, A. J. \& Guinotte, J. M. Global habitat suitability for framework-forming cold-water corals. PLoS ONE 6(4), e18483. https:// doi.org/10.1371/journal.pone.0018483 (2011).

4. Davies, A. J. et al. Downwelling and deep-water bottom currents as food supply mechanisms to the cold-water coral Lophelia pertusa (Scleractinia) at the Mingulay Reef Complex. Limnol. Oceanogr. 54, 620-629 (2009).

5. Xu, G., McGillicuddy, D. J. Jr., Mills, S. W. \& Mullineaux, L. S. Dispersal of hydrothermal vent larvae at East Pacific rise $9-10^{\circ} \mathrm{N}$ segment. J. Geophys. Res. Oceans 123, 7877-7895 (2018).

6. Bracco, A., Liu, G., Galaska, M., Quattrini, A. M. \& Herrera, S. Integrating physical circulation models and genetic approaches to investigate population connectivity in deep-sea corals. J. Mar. Syst. 198, 103189. https://doi.org/10.1016/j.jmarsys.2019.103189 (2019).

7. Kenchington, E. et al. Connectivity modelling of areas closed to protect vulnerable marine ecosystems in the northwest Atlantic. Deep Sea Res. I Oceanogr. Res. Pap. 143, 85-103 (2019).

8. Zeng, X., Adams, A., Roffer, M. \& He, R. Potential connectivity among spatially distinct management zones for bonefish (Albula vulpes) via larval dispersal. Environ. Biol. Fishes 102, 233-252 (2019).

9. Lange, M. \& van Sebille, E. Parcels v0.9: Prototyping a lagrangian ocean analysis framework for the petascale age. Geosci. Model Dev. 10, 4175-4186 (2017).

10. Knudby, A., Kenchington, E. \& Murillo, F. J. Modeling the distribution of Geodia sponges and sponge grounds in the northwest Atlantic. PLoS ONE 8(12), e82306. https://doi.org/10.1371/journal.pone.0082306 (2013).

11. Knudby, A., Lirette, C., Kenchington, E. \& Murillo, F. J. Species distribution models of black corals, large gorgonian corals and sea pens in the NAFO Regulatory Area. Ser. No. N6276. NAFO SCR Doc. 13/78 (2013). (Accessed 5 November 2020); https://www. nafo.int/Portals/0/PDFs/sc/2013/scr13-078.pdf.

12. Beazley, L., Kenchington, E., Yashayaev, I. \& Murillo, F. J. Drivers of epibenthic megafaunal composition in the sponge grounds of the Sackville Spur, northwest Atlantic. Deep Sea Res. I Oceanogr. Res. Pap. 98, 102-114 (2015).

13. Murillo, F. J., Kenchington, E., Lawson, J. M., Li, G. \& Piper, D. Ancient deep-sea sponge grounds on the Flemish Cap and Grand Bank, northwest Atlantic. Mar. Biol. 163, 63. https://doi.org/10.1007/s00227-016-2839-5 (2016).

14. Kenchington, E., Yashayaev, I., Tendal, O. S. \& Jørgensbye, H. Water mass characteristics and associated fauna of a recently discovered Lophelia pertusa (Scleractinia: Anthozoa) reef in Greenlandic waters. Polar Biol. 40, 321-337 (2017).

15. FAO. International Guidelines for the Management of Deep-Sea Fisheries in the High Seas p73 (FAO, Quebec, 2009).

16. NAFO. Conservation and Enforcement Measures. Ser. No. N6638. NAFO/FC Doc. $17 / 01$ (2017). (Accessed 5 November 2020); https://www.nafo.int/Portals/0/PDFs/fc/2017/CEM-2017-web.pdf.

17. Williams, J. C., Revelle, C. S. \& Levin, S. A. Spatial attributes and reserve design models: A review. Environ. Model. Assess. 10, $163-181(2005)$.

18. Yashayaev, I. Hydrographic changes in the Labrador Sea, 1960-2005. Prog. Oceanogr. 73, 242-276 (2007).

19. Yashayaev, I. \& Loder, J. W. Recurrent replenishment of Labrador Sea Water and associated decadal-scale variability. J. Geophys. Res. Oceans 121, 8095-8114 (2016).

20. Wang, S., Wang, Z., Lirette, C., Davies, A. \& Kenchington, E. Comparison of physical connectivity particle tracking models in the Flemish Cap region. Can. Tech. Rep. Fish. Aquat. Sci. 3353, 39 (2019).

21. Morato, T. et al. Climate-induced changes in the habitat suitability of cold-water corals and commercially important deep-sea fish in the North Atlantic. Glob. Change Biol. 26, 2181-2202 (2020).

22. Han, G. \& Wang, Z. Monthly-mean circulation in the Flemish Cap region: A modeling study. In Estuarine and Coastal Modeling: Proceedings of the Ninth International Conference on Estuarine and Coastal Modeling (ed. Spaulding, M. L.) 138-154 (American Society of Civil Engineers, Reston, 2006).

23. Han, G. et al. Seasonal variability of the Labrador current and shelf circulation off Newfoundland. J. Geophys. Res. Oceans 113, C10013. https://doi.org/10.1029/2007JC004376 (2008).

24. Maldonado, M. The ecology of the sponge larva. Can. J. Zool. 84, 175-194 (2006).

25. Wang, Z., Hamilton, J. \& Su, J. Variations in freshwater pathways from the Arctic Ocean into the North Atlantic Ocean. Progr. Oceanogr. 155, 54-73 (2017).

26. Ross, R. E., Nimmo-Smith, W. A. M. \& Howell, K. L. Increasing the depth of current understanding: Sensitivity testing of deep-sea larval dispersal models for ecologists. PLoS ONE 11(8), e0161220. https://doi.org/10.1371/journal.pone.0161220 (2016).

27. Wang, Z., Brickman, D. \& Greenan, B. J. W. Characteristic evolution of the Atlantic Meridional Overturning Circulation from 1990 to 2015: An eddy-resolving ocean model study. Deep Sea Res. I Oceanogr. Res. Pap. 149, 103056. https://doi.org/10.1016/j. dsr.2019.06.002 (2019)

28. Lazier, J. R. N. \& Wright, D. G. Annual velocity variations in the Labrador current. J. Phys. Oceanogr. 23, 659-678 (1993).

29. Hall, M. M., Torres, D. J. \& Yashayaev, I. Absolute velocity along the AR7W section in the Labrador sea. Deep Sea Res. I Oceanogr. Res. Pap. 72, 72-87 (2013).

30. Schneider, L. et al. Variability of Labrador Sea water transported through Flemish Pass during 1993-2013. J. Geophys. Res. Oceans 120, 5514-5533 (2015)

31. Varotsou, E., Jochumsen, K., Serra, N., Kieke, D. \& Schneider, L. Interannual transport variability of Upper Labrador Sea Water at Flemish Cap. J. Geophys. Res. Oceans 120, 5074-5089 (2015).

32. Layton, C., Greenan, B. J. W., Hebert, D. E. \& Kelley, D. Low-frequency oceanographic variability near Flemish Cap and Sackville Spur. J. Geophys. Res. Oceans 123, 1814-1826 (2018).

33. Wang, Z., Brickman, D., Greenan, B. J. W. \& Yashayaev, I. An abrupt shift in the Labrador current system in relation to winter NAO events. J. Geophys. Res. Oceans 121, 5338-5349 (2016).

34. Yashayaev, I. \& Loder, J. Further intensification of deep convection in the Labrador Sea in 2016. Geophys. Res. Lett. 44, 1429-1438 (2016).

35. Delandmeter, P. \& van Sebille, E. The parcels v2.0 Lagrangian framework: New field interpolation schemes. Geosci. Model Dev. 12, 3571-3584 (2019).

36. Brickman, D., Wang, Z. \& DeTracey, B. Variability of current streams in Atlantic Canadian Waters: A model study. Atmos. Ocean 54, 1-12 (2015).

37. Brickman, D., Hebert, D. \& Wang, Z. Mechanism for the recent ocean warming events on the Scotian Shelf of eastern Canada. Cont. Shelf Res. 156, 11-22 (2018).

38. Pepin, P., Han, G. \& Head, E. J. Modelling the dispersal of Calanus finmarchicus on the Newfoundland Shelf: Implications for the analysis of population dynamics from a high frequency monitoring site. Fish. Oceanogr. 22, 371-387 (2013). 
39. Le Corre, N., Pepin, P., Han, G., Ma, Z. \& Snelgrove, P. V. R. Assessing connectivity patterns among management units of the Newfoundland and Labrador shrimp population. Fish. Oceanogr. 28, 183-202 (2019).

40. Han, G. \& Kulka, D. Dispersion of eggs, larvae and pelagic juveniles of White Hake (Urophycis tenuis) in relation to ocean currents of the Grand Bank: A modelling approach. J. Northw. Atl. Fish. Sci. 41, 183-196 (2009).

41. Lynch, D. G. D. et al. Particles in the Coastal Ocean. Theory and Applications 389-452 (Cambridge University Press, Cambridge, 2014).

42. Murillo, F. J., Serrano, A., Kenchington, E. \& Mora, J. Epibenthic assemblages of the tail of the Grand Bank and Flemish Cap (northwest Atlantic) in relation to environmental parameters and trawling intensity. Deep Sea Res. I Oceanogr. Res. Pap. 109, 99-122 (2016)

43. Mariani, S., Uriz, M.-J. \& Turon, X. The dynamics of sponge larvae assemblages from northwestern Mediterranean nearshore bottoms. J. Plankton Res. 27, 249-262 (2005).

44. Mariani, S., Uriz, M.-J. \& Alcoverro, T. Dispersal strategies in sponge larvae: Integrating the life history of larvae and the hydrologic component. Oecologia 149, 174-184 (2006).

45. NAFO. Northwest Atlantic Fisheries Organization. Conservation and Enforcement Measures 2020. Ser. No. N7028. NAFO/COM Doc. 20-01 (2020). (Accessed 5 November 2020); https://www.nafo.int/Portals/0/PDFs/com/2020/CEM-2020-web.pdf.

46. Goldsmit, J. et al. Where else? Assessing zones of alternate ballast water exchange in the Canadian eastern Arctic. Mar. Pollut. Bull. 139, 74-90 (2019).

47. Kim, M. et al. Transit time distributions and storage selection functions in a sloping soil lysimeter with time-varying flow paths: Direct observation of internal and external transport variability. Water Resour. Res. 52, 7105-7129 (2016).

48. Gary, S.F. The Interior Pathway of the Atlantic Meridional Overturning Circulation. Doctor of Philosophy Thesis (Duke University, 2011). (Accessed 5 November 2020); https://dukespace.lib.duke.edu/dspace/handle/10161/4980.

49. Good, S. A., Martin, M. J. \& Rayner, N. A. EN4: Quality controlled ocean temperature and salinity profiles and monthly objective analyses with uncertainty estimates. J. Geophys. Res. Oceans 118, 6704-6716 (2013).

50. Boyer, T. P. et al. World Ocean Database 09. In NOAA Atlas NESDIS 66 (ed. Levitus, S.) (U.S. Government Printing Office, New York, 2009).

51. Wang, S., Wang, Z., Kenchington, E., Yashayaev, I. \& Davies, A. 3-D ocean particle tracking modeling reveals extensive vertical movement and downstream interdependence of closed areas in the northwest Atlantic. Mendeley Data https://doi.org/10.17632/ chfcjmnvcv.1 (2020).

\section{Acknowledgements}

This study was funded by the Fisheries \& Oceans Canada's International Governance Strategy Science Program through project "Science Advice in Support of the 2020 NAFO Review of Closed Areas to Protect Vulnerable Marine Ecosystems in the NRA" led by EK (2019-2021) and is a contribution towards the European Union's Horizon 2020 research and innovation program under Grant Agreement No. 679849 ('SponGES'), where this document reflects only the authors' view and the Executive Agency for Small and Medium-sized Enterprises (EASME) is not responsible for any use that may be made of the information it contains. We thank Dr. Pierre Pepin (Northwest Atlantic Fisheries Centre, Fisheries \& Oceans Canada, St. John's, Newfoundland and Labrador) and the NAFO Working Group on Ecosystem Science Assessment for valuable feedback on this work.

\section{Author contributions}

S.W., A.J.D., Z.W. and E.K. designed the work; Z.W. and I.Y. acquired data; S.W. undertook analyses; S.W., A.J.D. and E.K. drafted the work and all authors contributed to its revision and have approved the submitted version.

\section{Competing interests}

The authors declare no competing interests.

\section{Additional information}

Supplementary information is available for this paper at https://doi.org/10.1038/s41598-020-76617-x.

Correspondence and requests for materials should be addressed to E.L.K.

Reprints and permissions information is available at www.nature.com/reprints.

Publisher's note Springer Nature remains neutral with regard to jurisdictional claims in published maps and institutional affiliations.

(c) (i) Open Access This article is licensed under a Creative Commons Attribution 4.0 International License, which permits use, sharing, adaptation, distribution and reproduction in any medium or format, as long as you give appropriate credit to the original author(s) and the source, provide a link to the Creative Commons licence, and indicate if changes were made. The images or other third party material in this article are included in the article's Creative Commons licence, unless indicated otherwise in a credit line to the material. If material is not included in the article's Creative Commons licence and your intended use is not permitted by statutory regulation or exceeds the permitted use, you will need to obtain permission directly from the copyright holder. To view a copy of this licence, visit http://creativecommons.org/licenses/by/4.0/.

(c) Crown 2020 